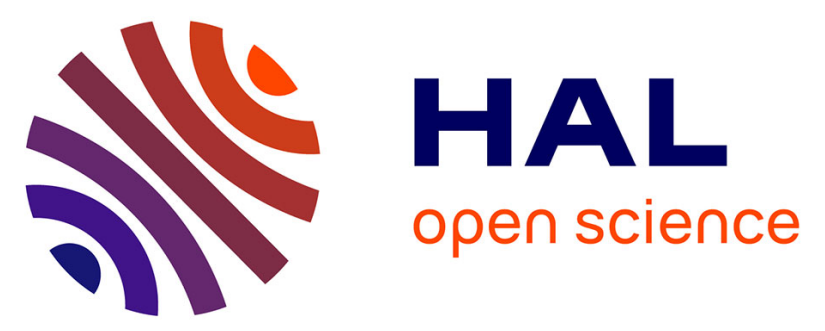

\title{
Future directions for advanced evapotranspiration modeling: Assimilation of remote sensing data into crop simulation models and SVAT models
}

A. Olioso, Y. Inoue, S. Ortega-Farias, J. Demarty, J.-P. Wigneron, I. Braud, Frédéric Jacob, P. Lecharpentier, C. Ottlé, J.-C. Calvet, et al.

\section{To cite this version:}

A. Olioso, Y. Inoue, S. Ortega-Farias, J. Demarty, J.-P. Wigneron, et al.. Future directions for advanced evapotranspiration modeling: Assimilation of remote sensing data into crop simulation models and SVAT models. Irrigation and Drainage Systems, 2005, 19 (3-4), pp.377-412. 10.1007/s10795-0058143-z . hal-03541150

\author{
HAL Id: hal-03541150 \\ https://hal.science/hal-03541150
}

Submitted on 24 Jan 2022

HAL is a multi-disciplinary open access archive for the deposit and dissemination of scientific research documents, whether they are published or not. The documents may come from teaching and research institutions in France or abroad, or from public or private research centers.
L'archive ouverte pluridisciplinaire HAL, est destinée au dépôt et à la diffusion de documents scientifiques de niveau recherche, publiés ou non, émanant des établissements d'enseignement et de recherche français ou étrangers, des laboratoires publics ou privés. 


\title{
Future directions for advanced evapotranspiration modeling: Assimilation of remote sensing data into crop simulation models and SVAT models
}

\author{
A. OLIOSO ${ }^{1}$, Y. INOUE ${ }^{2}$, S. ORTEGA-FARIAS ${ }^{3}$, J. DEMARTY ${ }^{1}$, \\ J.-P. WIGNERON ${ }^{4}$, I. BRAUD ${ }^{5}$, F. JACOB ${ }^{6}$, P. LECHARPENTIER ${ }^{1}$, \\ C. OTTLÉ ${ }^{7}$, J.-C. CALVET ${ }^{8} \&$ N. BRISSON ${ }^{1}$ \\ ${ }^{1}$ INRA-CSE, Domaine Saint-Paul, 84914 Avignon Cedex 9, France; \\ E-mail: olioso@avignon.inra.fr \\ ${ }^{2}$ NIAES, Ecosystem Research Group, Tsukuba, Japan \\ ${ }^{3}$ CITRA, Universidad de Talca, Chile \\ ${ }^{4}$ INRA, Bioclimatologie, Villenave d'Ornon, France \\ ${ }^{5}$ LTHE (UMR 5564 CNRS, INPG, IRD, UJF), Grenoble, FRANCE and CEMAGREF, \\ Lyon, France \\ ${ }^{6}$ ESAP, Toulouse, France \\ ${ }^{7}$ CETP, Vélizy, France \\ ${ }^{8}$ CNRM, Météo-France, Toulouse, France
}

\begin{abstract}
Soil-Vegetation-Atmosphere Transfer Models (SVAT) and Crop Simulation Models describe physical and physiological processes occurring in crop canopies. Remote sensing data may be used through assimilation procedures for constraining or driving SVAT and crop models. These models provide continuous simulation of processes such as evapotranspiration and, thus, direct means for interpolating evapotranspiration between remote sensing data acquisitions (which is not the case for classical evapotranspiration mapping methods). They also give access to variables other than evapotranspiration, such as soil moisture and crop production. We developed the coupling between crop, SVAT and radiative transfer models in order to implement assimilation procedures in various wavelength domains (solar, thermal and microwave). Such coupling makes it possible to transfer information from one model to another and then to use remote sensing information for retrieving model parameters which are not directly related to remote sensing data (such as soil initial water content, plant growth parameters, physical properties of soil and so on). Simple assimilation tests are presented to illustrate the main techniques that may be used for monitoring crop processes and evapotranspiration. An application to a small agricultural area is also performed showing the potential of such techniques for retrieving evapotranspiration and information on irrigation practices over wheat fields.
\end{abstract}

Key words: assimilation of data into models, crop simulation model, evapotranspiration, irrigation, remote sensing, soil-vegetation-atmosphere transfer model

\section{Introduction}

Crop models and Soil-Vegetation-Atmosphere Transfer Models (SVAT models) have been designed for analyzing the interactions between plant 
canopy processes and the environment. They give priceless information for production and yield monitoring, management of water resources, assessment of water requirements and more recently for carbon cycle studies in relation with climate research (a short description of some crop models and SVAT models is given in the next section). The use of such models over large areas is limited by our ability to provide them with the required input information. On one hand, it is almost impossible to obtain requisite plant and soil characteristics directly from networks of ground observations. On the other hand, remote sensing techniques can provide information on plant canopy processes that may be used for driving or constraining crop and SVAT models over large areas. These models may be operated without a systematic use of remote sensing data by intrinsically providing the means for interpolating energy and water fluxes or biomass production between remote sensing data acquisitions. Compared to classical methods for mapping evapotranspiration, based on models such as SEBAL (Bastiaanssen et al., 1998; Jacob et al., 2002a), the use of crop or SVAT models makes it possible to continuously monitor evapotranspiration along the whole crop cycle instead of estimating it for only snapshots derived from images. This is important since remote sensing data acquisitions may be infrequent. Moreover, it may be relatively easy to implement procedures to use data acquired by a large range of remote systems, differing in wavelength domains, acquisition time or geometry. Then, it may be possible to monitor evapotranspiration without using thermal infrared remote sensing data, which is not possible when using classical mapping methods. As a matter of fact, the evolution of crop structure, which may be obtained from reflectance data or radar data, may be sufficient for simulating evapotranspiration along the crop cycle. This feature is even enhanced when using dynamic-vegetation models that include the description of crop growth and its interaction with soil water content.

Remote sensing information on plant canopy processes is not direct because it results from the interaction of radiation with soil surface and plant canopy. It is then necessary to use specific radiative transfer models for interpreting these interactions and for relating plant and soil characteristics to remote sensing signals. These models range from very complex models to simplified approaches based on empirical relationships. For example, numerous relationships were established between spectral reflectances and LAI (Leaf Area Index), by means of vegetation indices; they can be used for estimating LAI that is then fed into crop or SVAT models. Such method, termed as 'forcing' method, has been described for examples by Delécolle et al. (1992) or Clevers et al. (2002) for driving crop models and by Sellers et al. (1996b) for driving a SVAT model used as a land surface parameterization in an atmospheric general circulation model (GCM). It requires that the driving variables are estimated from remote sensing data with a very fine time resolution, close to the time step of the model (or that they may be interpolated). 
However, most of plant and soil characteristics that are required for describing physical or biological processes cannot be related to remote sensing data through radiative transfer models (stomatal conductance, phenological parameters, soil physical parameters, soil moisture in the root zone, specific leaf area and so on). In order to estimate these 'hidden' quantities, it is first necessary to establish links between crop processes and remote sensing data by coupling crop, SVAT and radiative transfer models all together (Olioso et al., 1999a, 2001; Cayrol et al., 2000; Weiss et al., 2001; Verhoef \& Bach, 2003), and then, to apply mathematical techniques that make it possible to integrate remote sensing information into the coupled model. Such techniques are termed as assimilation techniques. They are widely used in the field of meteorology, where they have been developed to improve GCM predictions, in particular for weather forecast, by utilizing as much available observations as possible (WMO, 1995; Lorenc, 1997; Saunders, 1997). Their use in land crop and SVAT models is still at its beginning and has mostly been devoted to hydrologic applications such as river flow and flood forecast (e.g. Ottlé and Vidal-Madjar 1994; Houser et al., 1998; Reichle et al., 2001; François et al., 2003).

Until now, most of the studies devoted to assimilation of remote sensing data into crop models focused on the use of visible and near infrared reflectances or radar measurements (e.g. Moulin et al., 1998; Inoue et al., 1998; Chauki et al., 2000; Clevers et al., 2002; Verhoef \& Bach, 2003). Indeed, these measurements give information on crop structure and biomass seasonal dynamics. Thermal infrared (TIR) may also provide significant information on crop processes when water limitations occur, but as the assimilation of such data into crop model is not straightforward, only few attempts have been made (Moran et al., 1996; Cayrol et al., 2000; Olioso et al., 2001; Droogers \& Bastiaanssen 2002; Schuurmans et al., 2003). In the case of SVAT models, as they are based on the resolution of the energy balance equation, the use of TIR has been investigated in detail by many authors (e.g. Soer, 1980; Taconet \& Vidal-Madjar, 1988; Carlson et al., 1990; Camillo, 1991; Ottlé \& Vidal-Madjar, 1994; Taconet et al., 1995; Olioso et al., 1996b, 1999a). Both for crop and SVAT models, relatively few studies have analyzed the possible complementary assimilation of various wavelengths (Camillo, 1991; Bouman, 1992; Ottlé \& idal-Madjar, 1994; Clevers \& van Leeuwen, 1996; Moran et al., 1996; Olioso et al., 1999b; Cayrol et al., 2000; Olioso et al., 2001; Droogers \& Bastiaanssen, 2002; Prévot et al., 2003).

In this article, we will present how remote sensing data may be assimilated into SVAT or crop models with the objective of estimating crop evapotranspiration and soil water content. The potential for monitoring at the same time crop growth and irrigation will also be addressed. In the first part, we will briefly present crop and SVAT models and how they may be linked to 
remote sensing signals. In a second part, various assimilation techniques will be presented by means of simple examples. Assimilation of reflectances, TIR and radar remote sensing data into a SVAT model will be compared and the combination of reflectances and thermal infrared will illustrate the possible monitoring of crop evapotranspiration and irrigation events at the scale of a small agricultural area.

\section{Crop simulation models and SVAT models}

Crop models describe the main processes that occur during plant growth and crop production (similar models have also been developed to describe productivity of natural ecosystems or forest): phenology, photosynthesis, dry matter production, water processes, nitrogen processes, biomass partitioning, organ building, and solar radiation absorption. The typical time step of such models is 1 day, which is in agreement with the time scale of the simulated processes (crop growth and phenology). SVAT models are mainly used for estimating evapotranspiration, surface-energy exchanges and water balance components. Most of the transfer mechanisms (radiative, turbulent and water transfers) and some physiological processes (stomatal regulation) are described. Their time resolution is less than $1 \mathrm{~h}$ in agreement with the dynamics of atmospheric and surface processes. Note that this fine time resolution is also interesting when SVAT models are combined with remote sensing data, which are acquired instantaneously.

Numerous crop and SVAT models have been developed (e.g. see reviews by Sinclair \& Seligman, 1996; Olioso et al., 1999a). They may have very different complexity levels depending on the quantity and the detail of described processes. Recent advances in crop modelling make it possible to simulate a large variety of crops and a large variety of agricultural practices (Brisson et al., 2003). Specific description or parameterization may be required for each type of crop, even for models that aim to be generic. Such details are not available in SVAT models, even if the physical processes that are described (turbulent exchanges, water uptake) are not specific to plant species. However, as SVAT models have usually been designed for homogeneous surfaces, they are often difficult to use for describing heterogeneous systems such as orchards, vineyards, developing crops or savannah (cases in which they fail in the calculation of global turbulent exchange coefficients and global surface conductance for the vegetation layer). Another difficulty in the use of SVAT models results from insufficient detail in the description of the vegetation phenology. Usually, vegetation dynamic is only considered as an input. Because of a new interest in the study of $\mathrm{CO}_{2}$ fluxes in climatological and global change studies, some of the SVAT models have been extended to the simulation of photosynthesis (Olioso et al., 1996a; Sellers et al., 1996a; Calvet 
et al., 1998; Jacobs et al., 2003). The introduction of photosynthesis makes it possible to simulate biomass production and then evolution of crop structure such as LAI (such models are sometimes termed interactive-vegetation or dynamic-vegetation SVAT models). Four models, that have been developed in France, will be presented in this study: STICS, a crop model, ISBA, a simple SVAT model, ISBA-Ags, a dynamic-vegetation version of ISBA, and SiSPAT, a more complex SVAT model.

STICS (Simulateur mulTIdisciplinaire pour les Cultures Standard; in English Standard mulTIdisciplinary Simulator for Crops) is a crop model developed in France to simulate a wide range of crops (Brisson et al., 2003). It simulates crop growth and development as well as soil water and nitrogen balances driven by daily climatic data. It calculates both agricultural variables (yield, production quality, water and fertiliser consumption) and environmental variables (drainage and nitrogen leaching). From a conceptual point of view, STICS relies essentially on well-known relationships or on simplifications of existing models. One of the key elements of STICS is its adaptability to various crops made possible by the choice of generic parameters and options for both crop physiology and crop techniques. It is a daily time-step crop model. The data required to run the model include climate, soil (water and nitrogen initial profiles and permanent characteristics), crop management and species and varietal parameters. Soil is likened to a sequence of horizontal layers, each of which is characterised in terms of its water content, mineral nitrogen content and organic nitrogen content. Soil and crop interact via the roots, and these roots are defined with respect to root density distribution in the soil profile (root growth is accounted for). Crop growth is driven by the plant carbon functioning: solar radiation interception by the foliage and then transformation into aboveground biomass that is directed to the harvested organs during the final phase of the cycle. According to the plant type, crop development is driven either by a thermal index or a photothermal index. The development model is used to (i) make the LAI evolve and (ii) define the harvested organ filling phase. Water stress and nitrogen stress, if any, reduce leaf growth and biomass accumulation, based on stress indices that are calculated in water and nitrogen balance modules.

The ISBA (Interactions between Soil, Biosphere and Atmosphere) SVAT model was developed at Météo-France for being implemented as a land surface scheme in atmospheric weather forecast model and GCM (Noilhan \& Mahfouf, 1996). This model solves the surface-energy balance and the soil water balance with a 5 minute time step. The soil is described by one bulk reservoir corresponding to the maximum root zone (including a thin surface layer and regardless to actual root development) as proposed by Deardorff (1978), the various 'water and heat transfer coefficients' depending on soil texture. Drainage below the root zone has been introduced by Mahfouf and 
Noilhan (1996). The main surface variables simulated by ISBA are the surface temperature, the soil moisture in the root zone, the surface soil moisture and the energy fluxes. We may note that only one energy balance equation is solved, but that a separation of soil evaporation and plant transpiration is done on the basis of the vegetation fraction cover. The stomatal conductance depends on radiation, temperature, air vapour pressure deficit and soil moisture. ISBA requires meteorological variables, albedo, minimum stomatal resistance, LAI and vegetation height as inputs, as well as the soil texture, wilting point and field capacity.

In the ISBA-Ags version of ISBA (Ags holds for net assimilation and stomatal conductance, Calvet et al., 1998), a physiological stomatal resistance scheme is used to describe photosynthesis and its coupling with stomatal resistance at the leaf level. The computed net vegetation assimilation is used to feed a simple growth sub-model, and to predict the density of the vegetation cover. Compared to ISBA, three main new parameters are introduced in ISBA-Ags: leaf life expectancy (DE) and effective biomass per unit leaf area $(B / \mathrm{LAI})$ in the growth sub-model, and a mesophyll conductance $(\mathrm{gM})$. ISBA-Ags is able to simulate water budget, energy and mass fluxes $\left(\mathrm{CO}_{2}\right.$, sensible and latent heat fluxes, etc.) and LAI. Thus, the model is able to adapt the simulations of vegetation growth in response to changes in the environmental conditions (precipitation distribution, irrigation, water storage in the root-zone, atmospheric $\mathrm{CO}_{2}$ concentration, etc.) and, in contrast to ISBA, ISBA-Ags can be considered as an 'interactive-vegetation SVAT model' (or dynamic).

SiSPAT (Simple Soil Plant Atmosphere Transfer, Braud et al., 1995) is a SVAT model with a higher complexity level than ISBA. Coupled transfers of water and heat in the soil are described in more detail using the approach of Milly (1982), accounting for the vertical heterogeneity of soil structure and texture and root distribution. The soil prognostic variables are the vertical profiles of temperature and soil matrix water potential. This approach requires more complex information on the soil characteristics, such as retention curves and unsaturated hydraulic conductivity (for each soil layer). The effect of vegetation above the ground is based on the solution of two energy budgets, one for the ground surface and another one for the vegetation layer. Basic radiative transfer calculations are done inside the canopy to partition energy between the soil surface and the vegetation layer (using an attenuation coefficient). They require the separate prescription of albedo and emissivity values for the vegetation layer and the soil surface, the latter depending on the surface soil moisture. Calculation of turbulent heat fluxes follows the scheme used by Daamen and Simmonds (1994) (conversely to ISBA, no thermal roughness length is used). The circulation of water from the soil to the atmosphere through the plants and the soil water uptake by the roots follows an electrical 
analogue model as proposed by Federer (1979). The stomatal conductance is described as a function of vapour pressure deficit, leaf temperature, incident radiation and leaf water potential.

Many of the SVAT models and the crop models were developed, at least partly, for studying the interactions between water processes and crop production. So, they may be useful in irrigation management. For example, they have been used for studying the effect of different irrigation schedules on water use efficiency, to give recommendation on effective irrigation water management strategy, or for helping in decision making (Rinaldi, 2001; Nijbroek et al., 2003; Panda et al., 2003; Olioso et al., 2005; Guerra et al., 2005). If included in a spatialized framework, they may also be useful to analyze all the components of the water balance for a whole irrigation system, providing substantial information for water saving opportunities and strategies in irrigated agriculture (Droogers et al., 2000; Ines et al., 2002). In this frame, remote sensing may give access to the spatial variability and the time variation of information related either to crop development or crop water status, which may be used for driving crop and SVAT models (Moran et al., 1996; Droogers \& Bastiaanssen, 2002; Duchemin et al., 2002). In the following parts of this article, a modelling framework for relating remote sensing data to crop and SVAT models will be presented and assimilation procedures will be tested.

\section{Remote sensing signal models and coupling to crop and SVAT models}

Various types of remote sensing data may be used for driving crop and SVAT models: reflectances, TIR, microwave (active and passive). In order to analyse the complementary use of these remote sensing data and to implement assimilation procedures, simple radiative transfer models were coupled to STICS and ISBA-Ags (Figure 1). This was almost direct for simulating reflectances in the solar domain and backscattering coefficients in the microwave domain. A Beer-Lambert type model was used for simulating the Normalized Difference Vegetation Index (NDVI) from simulated LAI. This model was calibrated over a set of reference simulations by the SAIL canopy reflectance model (Scattering by Arbitrary Inclined Leaves designed by Verhoef 1984) applied to a large variety of canopies. Background effect of soil moisture was accounted for. NDVI is a combination of red $(r)$ and near infrared reflectances (nir) that may be used for quantifying vegetation amount (NDVI $=[\mathrm{nir}-r] /[\mathrm{nir}+r])$. In the microwave domain, a water cloud model was used to relate the vegetation integrated water content (estimated from LAI or dry biomass) and the surface soil moisture $(0-3 \mathrm{~cm})$ to backscattering coefficients (Wigneron et al., $1999 \mathrm{~b})$. In the case of thermal infrared and microwave emission, the coupling was more complex, at least for STICS. As this model did not describe the processes that determine surface temperature and as its daily time step was 

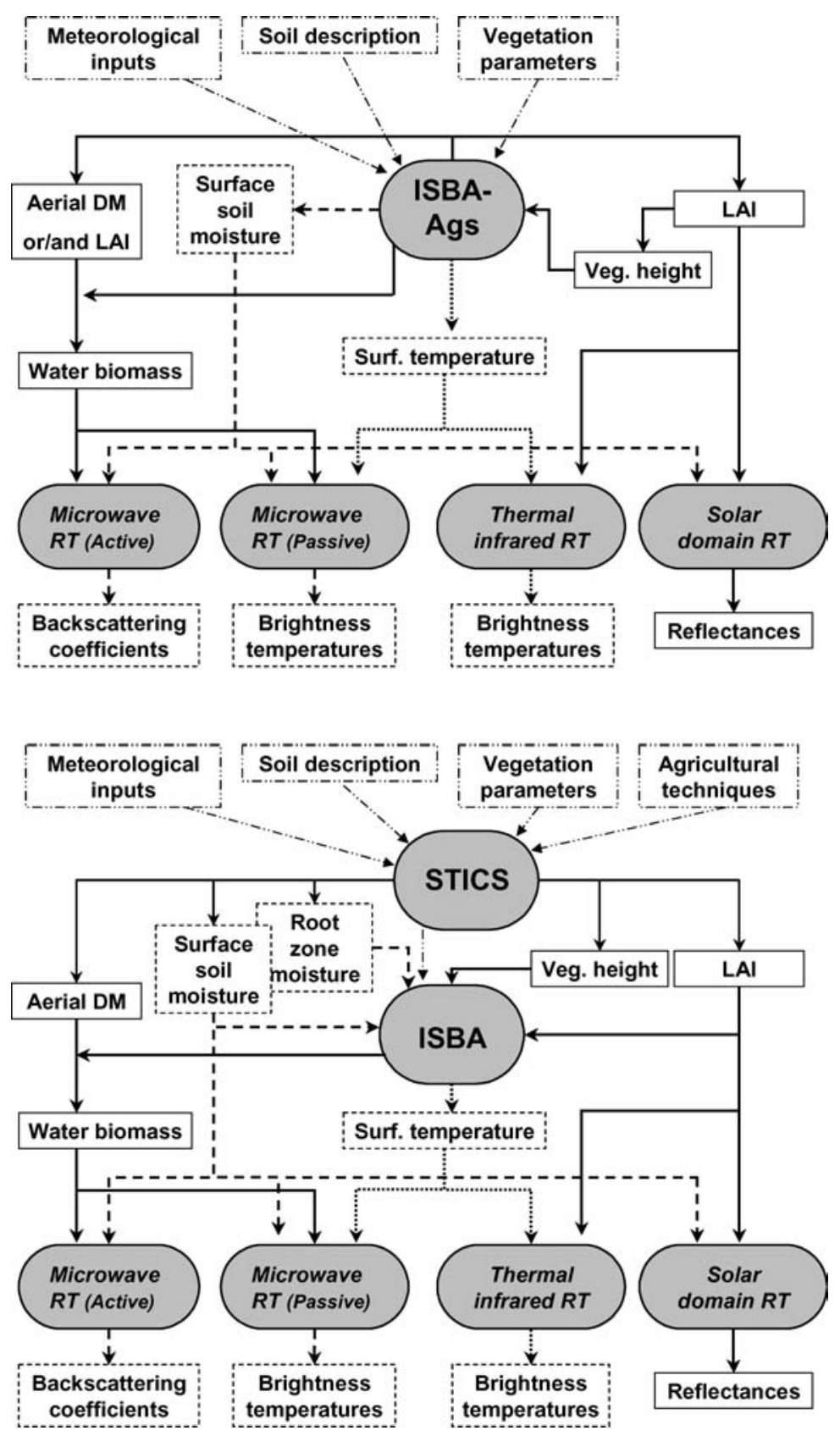

Figure 1. Scheme of coupling the different vegetation and radiative transfer models for simulating remote sensing signals in various wavelength domain. Top graph: coupling the ISBA-Ags dynamic-vegetation SVAT model to radiative transfer models. Bottom graph: coupling the STICS crop model to radiative transfer models (the ISBA SVAT model is used for interfacing STICS to radiative transfer models in the thermal infrared and the passive microwaves). 
not compatible with the fast response of these processes, it was necessary to use ISBA as an interface between STICS and radiative transfer models. For each simulation day, LAI and vegetation height were transferred from STICS to ISBA (Figure 1). Surface and root zone soil moistures simulated by STICS were also transferred to ISBA to be used as initial values for each simulation days. In the case of ISBA-Ags, the time step was adequate and a direct coupling to radiative transfer models was done. Calculation of TIR brightness temperature from surface temperature simulated by ISBA or ISBA-Ags was done by using an emissivity model depending on LAI (adapted from Olioso 1995a) and by accounting for the atmospheric radiation following the procedure described by Olioso (1995b). The microwave emission was simulated from surface temperature using the model proposed by Wigneron et al. (1995) using similar inputs as for active microwave simulations (integrated vegetation water content and surface soil moisture). The SiSPAT model has also been coupled to the SAIL radiative transfer model and to a simplified thermal model in order to simulate reflectances and thermal infrared signals by Demarty et al. (2002, 2005). It must be noticed that the simulation of surface temperature by ISBA requires the use of a roughness length for heat in addition to the classical roughness length for momentum in aerodynamic equations. Such parameter was not required in SiSPAT, which was based on a two-layer energy balance parameterization.

\section{Assimilation techniques}

Various techniques have been proposed for assimilating data into crop and SVAT models (Delécolle et al., 1992; Olioso et al., 1999a; François et al., 2001). One way consists of estimating model state variables from remote sensing data, and to directly introduce (force) them into the model at occurrences compatible with the time step of the model. This is called a forcing technique (Figure 2a). Other methods consist of correcting the course of model dynamic variables by comparing them to remote sensing measurements (Figure 2a). In sequential assimilation techniques, the model is updated each time an observation is available (e.g. Clevers et al., 2002; François et al., 2003). This observation is usually used for updating model prognostic variables. In variational assimilation techniques, all of the available observations for a certain period of time are processed together. They are usually used for retrieving model parameters or initial values of model variables using model calibration techniques (or recalibration in Figure 2b), based either on iterative algorithms (e.g. Wigneron et al., 1999a; Reichle et al., 2001; Nouvellon et al., 2001; Prévot et al., 2003; Verhoef \& Bach, 2003) or stochastic methods (Demarty et al., 2004 and 2005). Many different types of methodology and mathematical tools, such as Kalman filter (e.g. Reichle et al., 2003), adjoint model (e.g. 

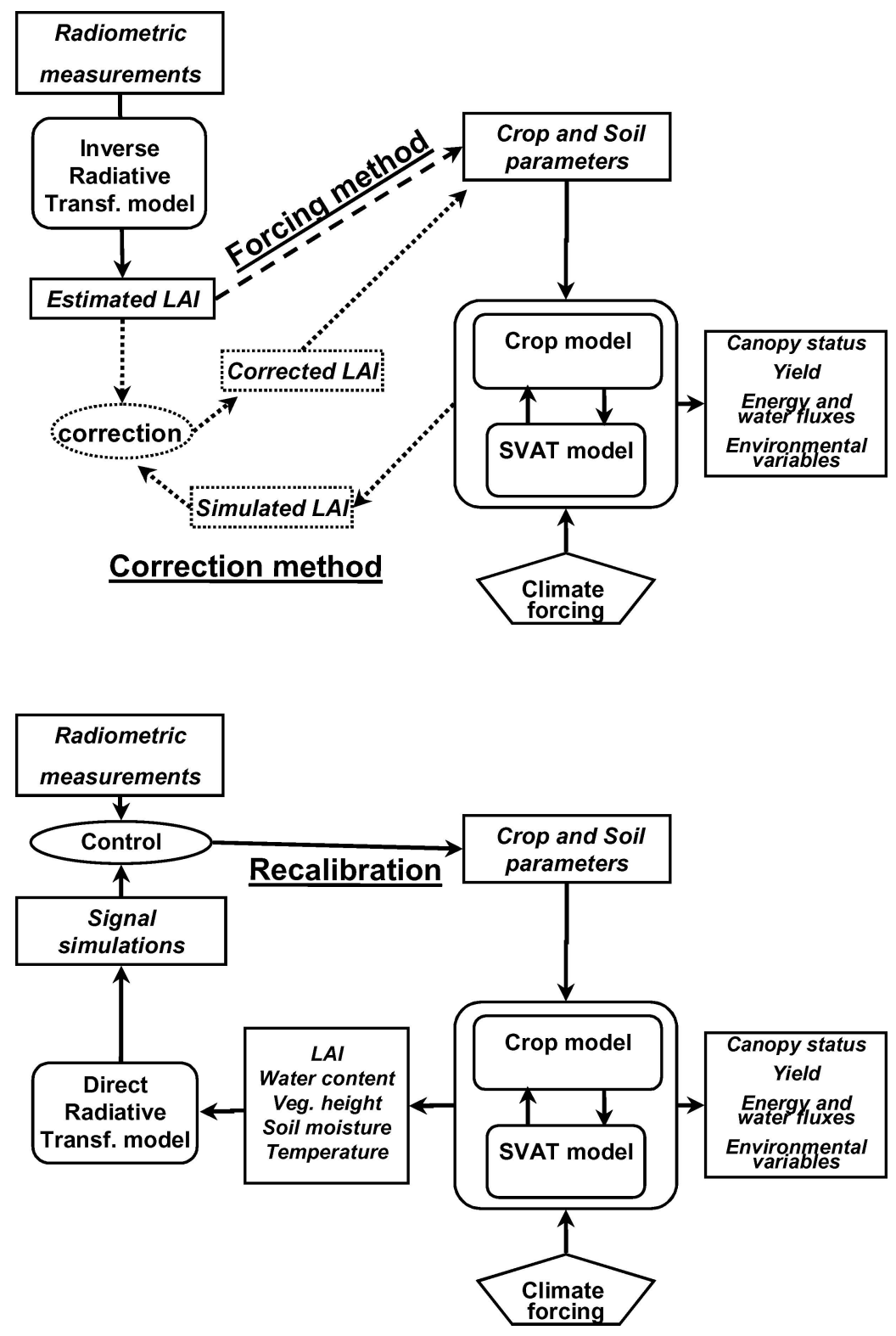

Figure 2. Schematic description of the various assimilation procedures presented in this article. Top graph: forcing method (dashed line) and correction method (doted lines) that may be used for implementing sequential assimilation. Bottom graph: recalibration method that may be used for implementing variational assimilation. 
Courtier \& Talagrand, 1990) have been developed for implementing assimilation procedures. Many of them have been employed in the fields of dynamic atmospheric modelling for a long time (in particular applied to numerical weather forecasts) and to a lesser extent for hydrological modeling. Their use for assimilating data in SVAT or crop models is just at its beginning (Viovy et al., 2001; Lauvernet et al., 2002).

In the following sections, after presenting datasets and illustrating model performances, simple examples of assimilation procedures will be presented and applied to the assessment of surface processes and evapotranspiration of a soybean crop. ISBA and ISBA-Ags models will be used in combination with reflectances, TIR and radar data. A second example will demonstrate the possible use of reflectances and TIR data to monitor evapotranspiration and irrigation events over wheat crops within a small agricultural area.

\section{Experimental data}

To test the various models and latter the assimilation of remote sensing data into these models, three experimental datasets were used: two local experiments in Avignon (South of France) on soybean crops (Olioso et al., 1996a,b) and a regional experiment in a small agricultural area $20 \mathrm{~km}$ south of Avignon performed in the frame of the Alpilles-ReSeDA program (Baret, 2002; Olioso et al., 2002a).

\section{Soybean experiments}

They were conducted in an experimental field at Avignon INRA Research Center. The crops were grown from the beginning of July (both years) to the end of October (1989) and to the end of September (1990). In 1989, the crop received $233 \mathrm{~mm}$ of water and the starting soil water content was close to field capacity. The crop reached a maximum LAI of 5.1. In 1990, the crop received $123 \mathrm{~mm}$ of water and the starting soil water content was also close to field capacity. The maximum LAI was 3.8. Meteorological data (air temperature, air humidity, wind speed, solar radiation, atmospheric radiation) and energy balance fluxes were monitored throughout both crop cycles with a $15 \mathrm{~min}$ averaging time. Sensible and latent heat flux were obtained from the Bowen ratio system described by Cellier and Olioso (1993) and from a monodimensional sonic anemometer combined with net radiation and ground heat flux measurements (Cellier \& Olioso, 1993; Ortega-Farias et al., 2004). Both methods gave very close results (root mean square differences lower than $25 \mathrm{~W} \mathrm{~m}^{-2}$ for the sensible heat flux and lower than $20 \mathrm{~W} \mathrm{~m}^{-2}$ for the latent heat flux). Soil and vegetation parameters (soil moisture, soil water potential, LAI, canopy height, crop biomass, rooting depth, soil and leaf optical 
properties and so on) were monitored with a daily or a weekly time step (Brisson et al., 1993; Bertuzzi et al., 1994; Taconet et al., 1995; Olioso et al., 1996a). Soil moisture was measured down to $1.8 \mathrm{~m}$ using a neutron probe, with three replicates, almost every day in 1989 and every 2 or 3 days in 1990. Surface soil moisture was assessed using gravimetric measurements in three layers $(0-0.05 \mathrm{~m}, 0.05-0.10 \mathrm{~m}$ and $0.10-0.20 \mathrm{~m})$. LAI and biomass were measured from three samples collected on an area of $0.25 \mathrm{~m}^{2}$ at least every week. Remote sensing data were acquired in the solar, thermal and microwave domains. Canopy reflectances were measured using CIMEL reflectometers held in vertical viewing at a height of $3.5 \mathrm{~m}$, every 3-4 days at solar noon. Twelve replicates with a sampling size of $0.2 \mathrm{~m}^{2}$ were performed in the three channels of the SPOT-HRV instrument (green: $500-590 \mathrm{~nm}$; red: 620-680 nm; near infrared: $790-890 \mathrm{~nm}$ ). The instruments were calibrated against a halon reference panel following the procedure described by Olioso et al. (1997). Infrared brightness temperatures were continuously measured using a thermal radiometer in the $8-14 \mu \mathrm{m}$ spectral range in vertical viewing (Heiman, KT17). The radiometer was set at $3 \mathrm{~m}$ high leading to a $6 \mathrm{~m}^{2}$ sampling area. It was calibrated against a black body before and after each experiment.

In 1989 active microwave measurements at C-band were also performed. The data were acquired by the scatterometer RAMSES, designed by the Centre National d'Etudes Spatiales (CNES), which was mounted on the mobile platform of a crane boom. The antenna height above the soil surface was $19.7 \mathrm{~m}$ and the resulting footprint varied from $3 \mathrm{~m}^{2}$ at nadir to $14 \mathrm{~m}^{2}$ at $50^{\circ}$ of incidence. The measurements used in this study were made at $5.3 \mathrm{GHz}$ at an incidence angle of $15^{\circ}$ ( $\mathrm{HH}$ polarization) and $23^{\circ}$ ( $\mathrm{HH}$ and VV polarization) at least every 2 days. The last configuration is very close to the configuration of the radar on board of ERS-1). About 50 independent measurements of backscattering coefficients were sampled along the 4 to $5 \mathrm{~m}$ track and were averaged. The absolute accuracy of the measurements was estimated to be about $\pm 1 \mathrm{~dB}$ by Bertuzzi et al. (1992).

\section{Alpilles-ReSeDA experiment}

The main objective of the ReSeDA project was the use of multisensor and multitemporal observations for monitoring soil and vegetation processes (including net primary production, yield, evapotranspiration and so on), in relation with the atmospheric boundary layer at local and regional scales, by assimilation of remote sensing data into crop simulation models and SVAT models. The experiment included field measurements, aircraft and satellite data acquisitions, covering the whole growing season of winter and summer crops (October 1996 to November 1997). The site had an area of $4 \mathrm{~km}$ by $5 \mathrm{~km}$ and 
was located near the Alpilles Hills $20 \mathrm{~km}$ South of Avignon. The main crops were wheat, sunflower, orchards, vegetables and forage. The various ground data collected were described in detail by Olioso et al. (2002a). Remote sensing data were collected at various wavelength ranges using spaceborne sensors (NOAA-AVHRR, Landsat-ETM+, SPOT-HRV, ERS and RADARSAT) and airborne sensors (the visible and near-infrared multiangular radiometer POLDER, a thermal infrared camera INFRAMETRICS 760, an airborne multiangle scatterometer ERASME). The main data used in this study were obtained from POLDER and INFRAMETRICS airborne sensors (reflectances and TIR data) and ground measurements (meteorological data and soil moisture data). Both instruments flew on days with clear sky around solar noon, approximately 1-2 times per month at altitudes of $3000 \mathrm{~m}$ and/or $1500 \mathrm{~m}$. Twenty-seven flight acquisitions were performed between March and October (corresponding to 18 different days). After spatial registration and atmospheric correction, the spatial resolution of the images was $20 \mathrm{~m}$. As both instruments acquired multi-directional data, specific procedures were used for generating bi-directional reflectance distribution functions from POLDER images, and nadir thermal infrared brightness temperature from the INFRAMETRICS camera. A more detailed description of remote sensing data acquisition procedures, sensor calibrations and data preprocessing was given by Jacob et al. (2002a, b). The calibration of the INFRAMETRICS camera included a careful check using thermal brightness temperature measured at the ground level in several (three to six) fields using Heiman KT15 and KT17 thermal radiometers.

Field measurements of vegetation and soil characteristics were performed in three wheat and three sunflower fields (see Olioso et al., 2002a,d). Among them, the characterisation of soil hydrodynamical properties, such as retention curve and unsaturated hydraulic conductivity, were used in this study for calculating wilting point and field capacity. Soil moisture and soil water potential were measured every week in the same fields down to $1.4 \mathrm{~m}$ with three replicates, using neutron probe, capacitive probe, and tensiometer (automatic and manual). Soil moisture measurements were calibrated against gravimetric measurements in order to be representative of the field scale (Olioso, et al. 2002a). Meteorological data required for running models were acquired using a meteorological station set near the center of the Alpilles test area.

\section{Some illustrations of the simulations performed with coupled crop-SVAT-radiative transfer models}

Figure 3 presents simulations of evapotranspiration and LAI by STICS, ISBA, ISBA-Ags and SiSPAT (actually, LAI was used as an input in ISBA and SiSPAT and not simulated) for the soybean crop in 1990. Information for 

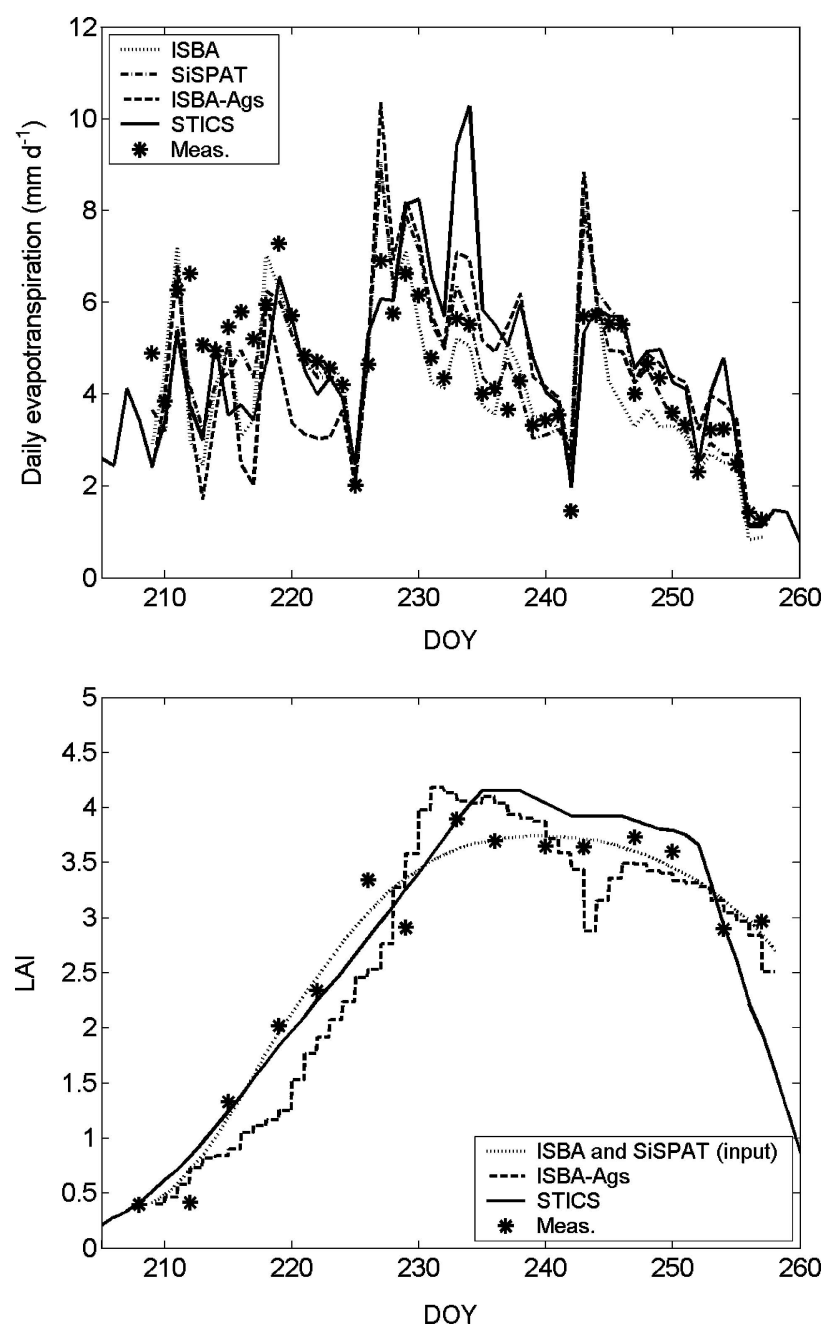

Figure 3. Simulation of daily evapotranspiration and LAI using STICS, ISBA, ISBA-Ags and SiSPAT for a soybean crop in Avignon in 1990. N.B.: LAI is not simulated by ISBA and SiSPAT, but used as an input. DOY is Day of Year and $\left({ }^{*}\right)$ represents the measured data.

driving the models was derived from the measured data (meteorological data: air temperature, air vapor pressure and wind speed measured at around 2-m above the crop, solar radiation and atmospheric radiation, soil moisture at the beginning of the simulation, soil physical properties according to model needs, profiles of root density for SiSPAT, maximum root depth for ISBA (around $1.5 \mathrm{~m})$ ). Despite the differences between models, close results were usually obtained. It is important to notice that in this case, calibration of the models were done, either on the experimental data of soil moisture and LAI 
for ISBA and ISBA-Ags, or from the parameterization of a more complex model (SOYGROW) for STICS (Brisson et al., 2003). The calibration methods differed from one model to another and no attempts were made to unified them. They were described by Wigneron et al. (1999a) for ISBA, Calvet et al. (1998) for ISBA-Ags and Braud et al. (2005) for SiSPAT. The main calibrated parameters were the saturated hydraulic conductivity and the total plant resistance in SiSPAT, the wilting point, the field capacity, the minimum stomatal resistance, the thermal roughness length in ISBA, the leaf life expectancy $(\mathrm{DE})$, the effective biomass per unit leaf area $(B / \mathrm{LAI})$ and the mesophyll conductance (gM) in ISBA-Ags. Olioso et al. (2002d) also describe how SiSPAT and ISBA may be calibrated. We can also notice on Figure 3 that most models, and particularly SVAT models, had difficulties in simulating the evapotranspiration at the beginning of the crop cycle, when LAI was low. No specific calibration was performed to fix this problem.

Examples of remote sensing data simulations with the coupled model in the condition of the soybean experiment in 1990 are displayed in Figure 4 (reflectances, thermal infrared brightness temperature and microwave backscattering coefficients). They show an overall agreement between measurements and simulations of reflectances (expressed in terms of NDVI) and maximum TIR brightness temperature (conversely to SVAT and crop models, no specific calibrations were performed for the radiative transfer models over the 1990 dataset). The overestimation of NDVI at some periods was actually linked to the particular leaf movements that occurred as a response to water stress for this soybean cultivar (Labrador with a very short cycle). Such response was not accounted in ISBA-Ags or STICS. Simulations of microwave backscattering coefficients qualitatively agreed with the data presented by Wigneron et al. (1999b) for the soybean experiment in 1989. Simulations of microwave emission are not presented here because that type of data is not available in operational or expected remote sensing system with a spatial resolution compatible with agricultural applications at the field scale (pixel size is several hundreds of $\mathrm{km}^{2}$ ). However, simulations were presented before by Olioso et al. (2001) on soybean and Wigneron et al. (2002) on wheat.

\section{Simple examples of assimilation on the soybean experiment in 1989 dataset}

We have shown before that several types of assimilation procedures have been developed. The three main types, including forcing, sequential and variational methods, have been applied to ISBA and ISBA-Ags over the 1989 soybean experiment dataset and are presented here (ISBA and ISBA-Ags being calibrated over other experiments). Results are compiled in Table 1. 

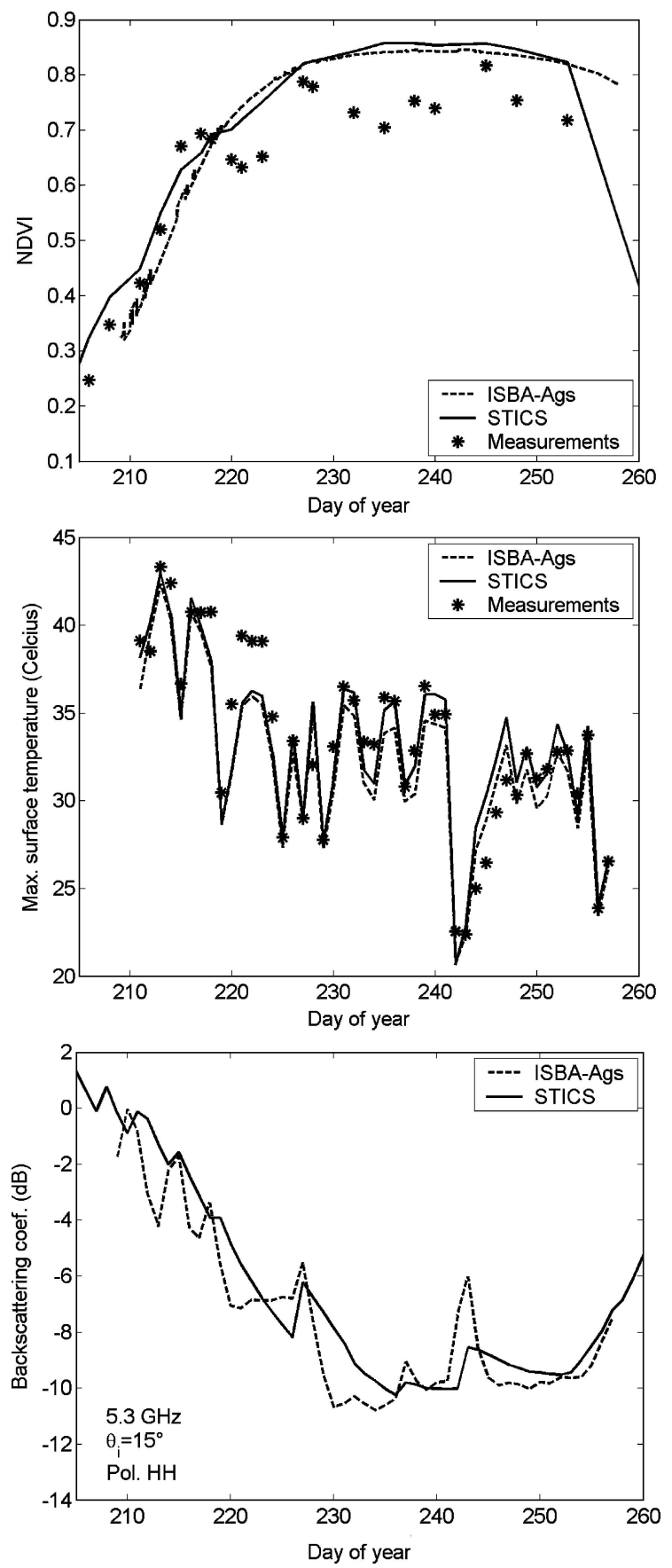

Figure 4. Simulation of remote sensing data over the soybean 1990 dataset with the coupled crop-SVAT-radiative transfer models presented in Figure 1 (based either on the ISBA-Ags SVAT model or the STICS crop model). 
Table 1. Performances of ISBA and ISBA-Ags retrieval of evapotranspiration over the soybean experiment in 1989.

\begin{tabular}{llc}
\hline & $\begin{array}{l}\text { RMSE on ET } \\
\left(\mathrm{mm} \mathrm{d}^{-1}\right)\end{array}$ & $\begin{array}{l}\text { Bias on ET } \\
\left(\mathrm{mm} \mathrm{d}^{-1}\right)\end{array}$ \\
\hline Forcing method & & -0.7 \\
$\quad$ LAI forced into ISBA & 1.1 & -0.5 \\
$\quad$ LAI forced into ISBA-Ags & 1.2 & -0.1 \\
Sequential assimilation & 1.0 & 0.5 \\
$\quad$ Sequential-full correction-Avignon calibration & 1.4 & -0.3 \\
$\quad$ Sequential-full correction-HAPEX calibration & & -0.2 \\
Variational assimilation & 0.8 & -0.5 \\
$\quad$ Initial soil moisture recalibration from TIR & 0.9 & 0.1 \\
$\quad$ Initial soil moisture recalibration from Radar & 1.2 & \\
$\quad$ Initial soil moisture recalibration from NDVI & 1.0 & \\
$\quad$ Crop growth parameters recalibration from Radar & & \\
\hline
\end{tabular}

Note. N.B.: measured ET varied between 1 and $8 \mathrm{~mm} \mathrm{~d}^{-1}$ (and maybe higher for days without measurements as suggested by model results); very high evapotranspiration rate were obtained when a very strong and dry wind was blowing (called Mistral).

\section{Forcing method}

We estimated LAI from NDVI, and then forced LAI information into ISBA and ISBA-Ags. The LAI production module in ISBA-Ags was short cut. The LAI-NDVI model was calibrated before on independent datasets acquired on soybean in Avignon in 1987 and 1990. It gave very good estimates of LAI on the 1989 dataset (Figure 5). Simulated evapotranspiration (ET) was in good agreement with the measurements despite a significant underestimation due to difficulties at low LAI and during the senescent period (Figure 5 and Table 1).

\section{Sequential assimilation}

The LAI estimated from NDVI was used for correcting ISBA-Ags simulations. In this case, the LAI production module was on, and the simulated LAI was compared to the LAI estimated from NDVI at four dates along the 1989 soybean crop cycle. Basic sequential assimilation procedures were used (Figure 6): (i) a full correction was done assuming that LAI was estimated with no error from remote sensing data; LAI simulation was restarted from the remote sensing values each time they were available; (ii) a half way correction was done assuming that LAI was both simulated and estimated with some error; LAI simulation was restarted from the average of the estimated and the simulated values. When the two procedures were applied to ISBA-Ags calibrated on the 1990 experiment, the use of remote sensing data to correct the time variation of LAI had only a low effect on LAI values (Figure 6), as well as 

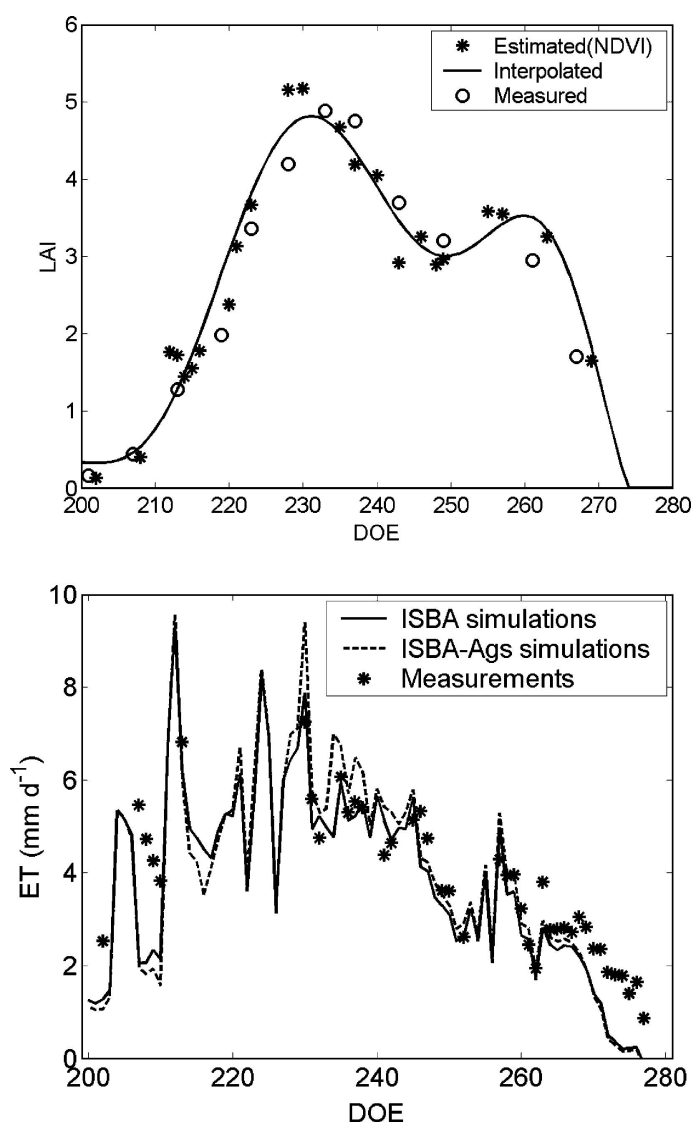

Figure 5. Top graph: estimation of soybean LAI temporal profile from NDVI in 1989; comparison to the measured data (o). Bottom graph: simulation of soybean evapotranspiration in 1989 by forcing estimated LAI into ISBA and ISBA-Ags (short cutting the plant growth submodel). DOE is Day of Experiment (starting at the beginning of the year).

on ET and water reserve simulations (not shown). However, in the case of the full correction, results on ET were slightly improved (Table 1).

The full correction procedure was also applied to ISBA-Ags calibrated by Calvet et al. (1998) on the soybean dataset of the HAPEX-MOBILHY experiment in the South-West of France. The calibrated parameters were very different from those obtained on the 1990 Avignon experiment (Table 2). The higher values of leaf life expectancy (DE) and effective biomass per unit leaf area $(B / \mathrm{LAI})$ were responsible for a fast increase and unrealistic values (up to 12) of simulated LAI (Figure 7). Despite that the mesophyll conductance (gM) was significantly lower, the high LAI generated large increases in evapotranspiration and soil water depletion (Figure 7). When correction of the LAI time course from NDVI was performed (full correction at four dates), water up- 
Table 2. ISBA-Ags parameters calibrated on two datasets (from Calvet et al., 1998) and parameters retrieved from variational assimilation of Radar data in 1989.

\begin{tabular}{llll}
\hline Calibration dataset & $\mathrm{gM}\left(\mathrm{mm} \mathrm{s}^{-1}\right)$ & $\mathrm{DE}$ (day) & $\mathrm{B} / \mathrm{LAI}\left(\mathrm{g} \mathrm{m}^{-2}\right)$ \\
\hline HAPEX-MOBILHY & 1 & 250 & 63 \\
Avignon 1990 & 2.87 & 15 & 25 \\
Crop growth parameters & $2.87^{*}$ & 17 & 33 \\
$\quad$ recalibration from Radar & & & \\
\hline
\end{tabular}

* In this case, gM was set to the value calibrated in 1990 and not retrieved from Radar data.

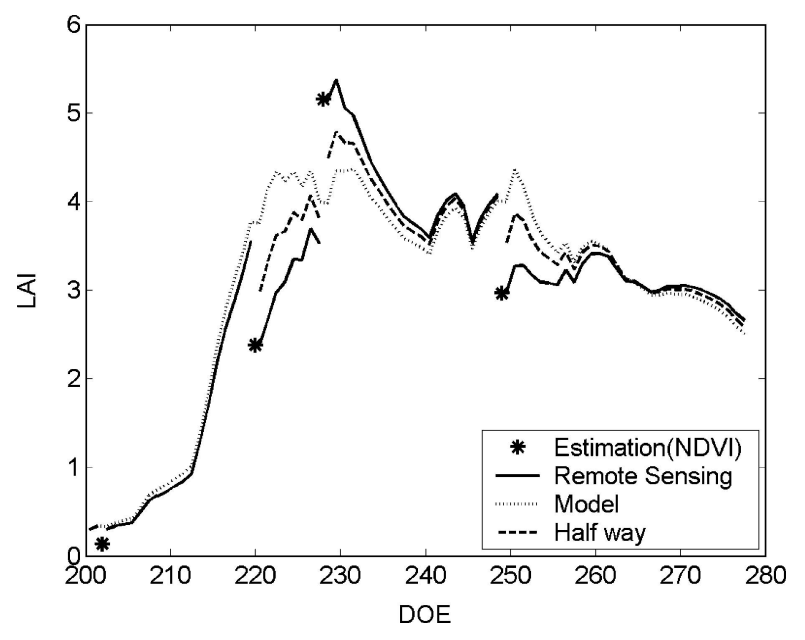

Figure 6. Simulated LAI from sequential assimilation of LAI in ISBA-Ags for the soybean experiment in 1989 (the model was calibrated over the Avignon 1990 dataset). Three correction levels of the simulations are displayed: full correction (termed 'Remote Sensing'), no correction (termed 'Model') and half correction. DOE is Day of Experiment (starting at the beginning of the year).

take was significantly decreased. However, as fast increases of LAI were still simulated after each correction (DE and $B /$ LAI being still large), evapotranspiration and water depletion were still higher than with the parameters calibrated on the 1990 Avignon experiment (Figure 7 and Table 1). If the number of remote sensing estimations of LAI was increased (not shown), simulations were improved since corrections were applied more often, limiting LAI increase and water uptake. It must be noticed that the large differences between the two sets of calibrated parameters (Table 2) might be explained by erroneous measurements performed during the HAPEX-MOBILHY experiment. As a matter of fact, if variations in calibrated parameters may be expected due to varietal differences (e.g. length of the crop cycle), they must be in a limited range. Other calibrations performed on several soybean experiments in Japan 

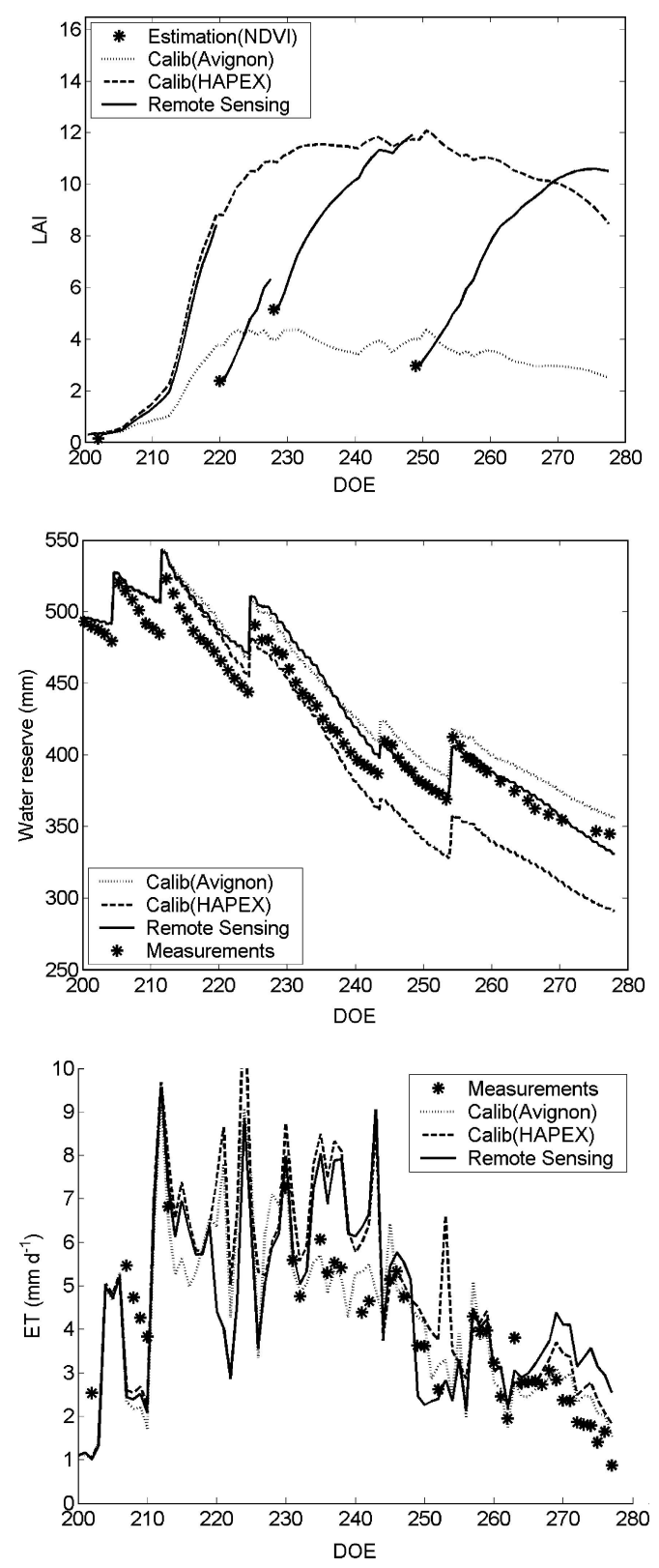

Figure 7. Simulated LAI, soil water reserve and evapotranspiration (ET) from sequential assimilation of LAI into ISBA-Ags for the soybean experiment in 1989. The model was calibrated using the HAPEX-MOBILHY dataset. Two correction levels are displayed: full correction (termed 'Remote Sensing'), no correction (termed 'Calib(HAPEX)'). Simulation using the calibration over the Avignon 1990 dataset are displayed for comparison (termed 'Calib(Avignon)'). The soil water reserve corresponded to a soil layer down to the maximum root depth, $1.5 \mathrm{~m}$ in this case. DOE is Day of Experiment (starting at the beginning of the year). 
(Inoue and Olioso, 2004) led to calibrated values rather close to the values obtained in Avignon. However, it was interesting to show that the use of correction procedures may significantly improve evapotranspiration simulations obtained with an ill-calibrated model.

\section{Variational assimilation}

We used ISBA-Ags calibrated on the Avignon-1990 dataset and coupled to the radiative transfer models for simulating remote sensing signals in 1989 (NDVI, TIR, backscattering coefficients). The initial soil water content was adjusted so that signal simulations fit with the remote sensing measurements. Indeed, the water content at the beginning of the simulation may be one of the major unknowns when monitoring crop evapotranspiration and growth from remote sensing data over an agricultural area. Almost 20 NDVI measurements, 40 TIR measurements and 40 backscattering coefficient measurements were available during the experiment. RMSE for the different signals were reaching their lowest values, indicating the best agreement between simulated and measured signals, for high values of initial water content (NDVI $\rightarrow 0.28 \mathrm{~m}^{3} \mathrm{~m}^{-3}$; $T_{s} \rightarrow 0.31 \mathrm{~m}^{3} \mathrm{~m}^{-3}$; radar $\rightarrow 0.32 \mathrm{~m}^{3} \mathrm{~m}^{-3}$ ), which was in agreement with the real situation $\left(0.31 \mathrm{~m}^{3} \mathrm{~m}^{-3}\right)$. This resulted in almost similar estimations of evapotranspiration by using TIR or radar measurements (RMSE and Bias in Table 1, Figure 8). The results obtained from NDVI were less satisfactory. Figure 8 also displays results obtained for LAI, soil water reserve and evapotranspiration. The differences between the results obtained from TIR (or radar) data and NDVI data were explained by a faster increase in retrieved LAI at the beginning of the crop cycle that compensated for the usual underestimation of ET at low LAI. From these results, it was apparent that the crop growth parameters (DE and $B / \mathrm{LAI}$ ) calibrated on the 1990 dataset were not fully valid for application to the soybean crop in 1989.

Variational assimilation procedure may also be used for retrieving plant parameters. Figure 9 illustrates the results obtained on the same soybean dataset while retrieving crop growth parameters (DE and $B / \mathrm{LAI}$ ) from radar measurements (the initial soil moisture being known and the mesophyll conductance set to the value calibrated in 1990). The time variation of LAI was better simulated and evapotranspiration was satisfactorily retrieved (Table 1 and Figure 9). Once again, nearly similar results were obtained for the three types of remote sensing data (not shown). Other results obtained by Inoue and Olioso, 2004 using NDVI on a soybean crop in Japan showed that it was possible to retrieve $\mathrm{CO}_{2}$ fluxes above the crop, as well as to separate vegetation transpiration from soil evaporation. In a final step, we tried to determine simultaneously initial soil moisture and crop growth parameters. This attempt has not been successful because of compensations occurring between the various 

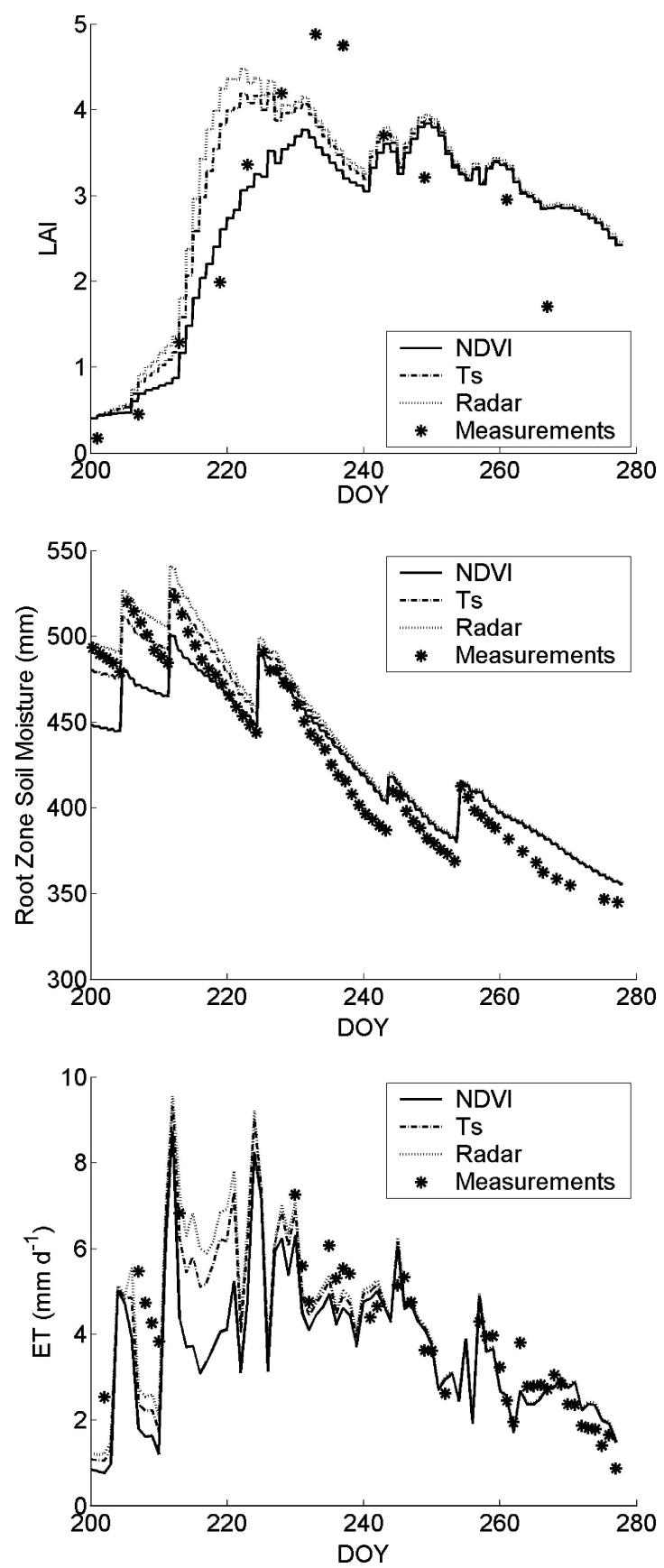

Figure 8. Simulated LAI, water reserve and evapotranspiration (ET) after retrieving the initial soil water content from variational assimilation of NDVI, surface temperature $\left(T_{S}\right)$ or microwave backscattering coefficients (Radar) into ISBA-Ags for the soybean experiment in 1989 (the model was calibrated over the Avignon 1990 dataset). DOY is Day of Year. 

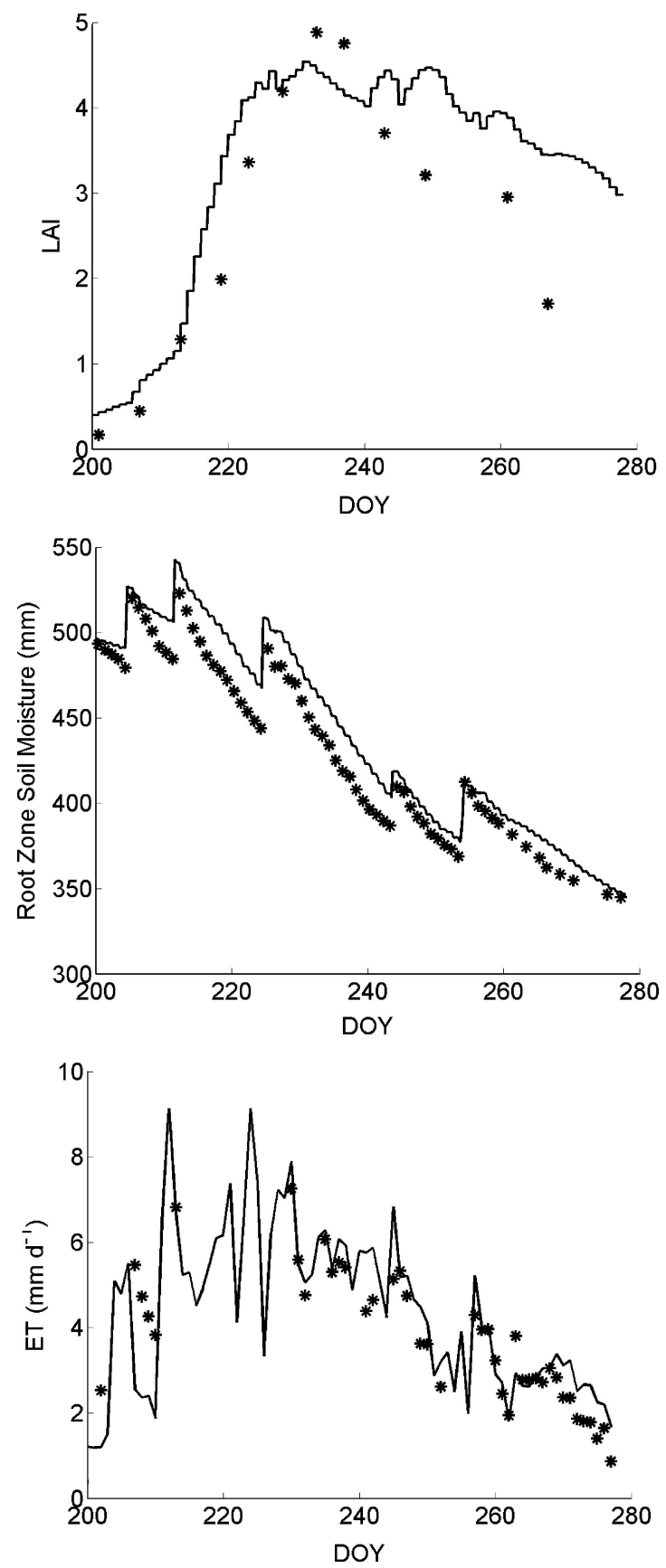

Figure 9. Simulated LAI, water reserve and evapotranspiration (ET) after retrieving the crop growth parameters (B/LAI and $\mathrm{DE})$ from variational assimilation of microwave backscattering coefficients (Radar) into ISBA-Ags for the soybean experiment in 1989. DOY is Day of Year, $(*)$ represents the measurements and the solid line the simulations. 
parameters: different sets of parameters may lead to similar remote sensing signals (e.g. a low initial water content, inducing water stress, was counterbalanced by a higher vegetation growth rate, leading to quite conservative changes in LAI and water extraction). Olioso et al. (1999a,b) obtained similar results using a different model and a different assimilation procedure. However, we hope to break the compensation mechanisms by using a combination of the remote sensing signals in the different spectral domains.

\section{Application to the monitoring of wheat evapotranspiration and irrigation events over an agricultural area}

Evapotranspiration of wheat crop was monitored using a combination of forcing and variational assimilation of reflectance data and thermal infrared data into the ISBA model over the Alpilles test site. There were 92 wheat fields representing $30 \%$ of the surface. After a wet winter, these crops experienced a very dry climate since no rain was recorded between end of January and end of April. High-water stress was recorded and irrigation was performed in some fields, which was not usual for the area (Olioso et al., 2002a). Irrigation consisted only in letting water run over an entire field for 1-3 consecutive days.

In a first step, reflectance data were used for retrieving LAI by means of a neural net technique (Weiss et al., 2002) and vegetation height using a calibrated relationship between TSAVI vegetation index (Transformed Soil Adjusted Vegetation Index) and ground measurements of height in some fields (Olioso et al., 2002b). Like NDVI, TSAVI combines red and near infrared reflectances (Baret \& Guyot, 1991). It includes information on the soil reflectance through the 'soil line' concept, so that it is almost insensitive to soil background effect, even at low LAI. Conversely, NDVI may change if soil surface reflectance changes due to variations in surface soil moisture or soil roughness. As energy flux calculation is very sensitive to error on the determination of vegetation height at low vegetation cover, we preferred to use TSAVI instead of NDVI. Leaf Area Index and vegetation height were interpolated daily from January to June 1997 and forced into ISBA. Main ISBA vegetation parameters were set to standard values for wheat (see Olioso et al., 2002d): minimum stomatal resistance, $r_{\mathrm{smin}}=50 \mathrm{~m} \mathrm{~s}^{-1}$; thermal roughness $\left(z_{\mathrm{oh}}\right)$ as a fraction of momentum roughness $\left(z_{\mathrm{om}}\right), z_{\mathrm{oh}}=z_{\mathrm{om}} / 54$; albedo, $\alpha=0.22$; depth of the root zone, $d_{\mathrm{rz}}=1.40 \mathrm{~m}$. Soil properties were set to their average values derived for the wheat fields in the central zone of the Alpilles site (where most of the ground investigation was performed): wilting point, $w_{\mathrm{wp}}=0.240 \mathrm{~m}^{3} \mathrm{~m}^{-3}$ and field capacity $w_{\mathrm{fc}}=0.366 \mathrm{~m}^{3} \mathrm{~m}^{-3}$ (Olioso et al., 2002d). Initial water content was set to field capacity over the area since winter was very wet. 
In a second step, TIR brightness temperatures simulated by ISBA were compared to airborne INFRAMETRICS measurements. It appeared that in most fields, simulated temperatures were higher than measurements, illustrating that predicted soil water content was not high enough. Several reasons might be responsible for this "lack" of water, e.g. (i) water holding by the soil was higher than prescribed, either because of prescribed field capacity was too low, or prescribed wilting point was too high; (ii) root depth was larger than prescribed $(1.40 \mathrm{~m})$; (iii) water transfers from the water table occurred; (iv) irrigation was used.

In a third step, it was possible, for some fields, to notice a drop in measured brightness temperature between two successive INFRAMETRICS measurements, which was not possible to simulate with ISBA without accounting for an irrigation event between the two measurements (Figure 10). For fields where this behaviour was noticed, we derived an irrigation amount by comparison to a field in which we knew that no irrigation was applied (this explains the differential presentation in Figure 10). Irrigation was identified in several fields and the derived supplies were larger than $50 \mathrm{~mm}$ (Figure 11). This was in agreement with qualitative ground observations. Model simulations were then corrected by adding these irrigation supplies to the soil water reserve (sequential assimilation).

In a fourth step, the global level of simulated temperatures was adjusted to the INFRAMETRICS measurements (variational assimilation) for each

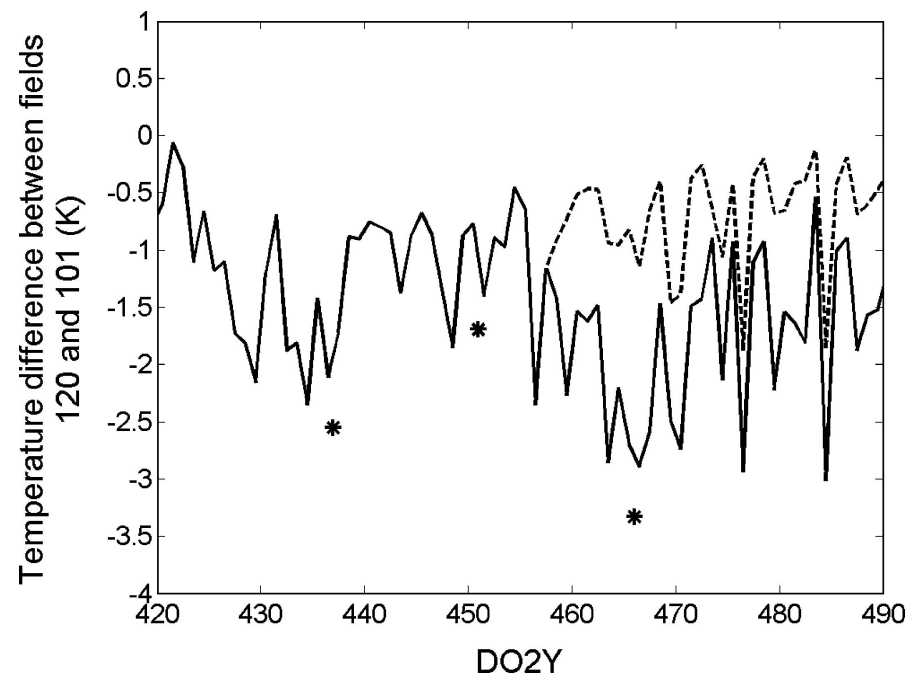

Figure 10. Temperature difference between wheat field 120 (irrigated) and wheat field 101 (non-irrigated) in the Alpilles area; dashed line: ISBA simulation assuming field 120 is not irrigated; solid line: ISBA simulation after introducing irrigation on DO2Y 458. (DO2Y stands for the number of Days for 2 Years). Asterisks (*) represent the measured temperature differences thanks to the INFRAMETRICS thermal infrared camera. 


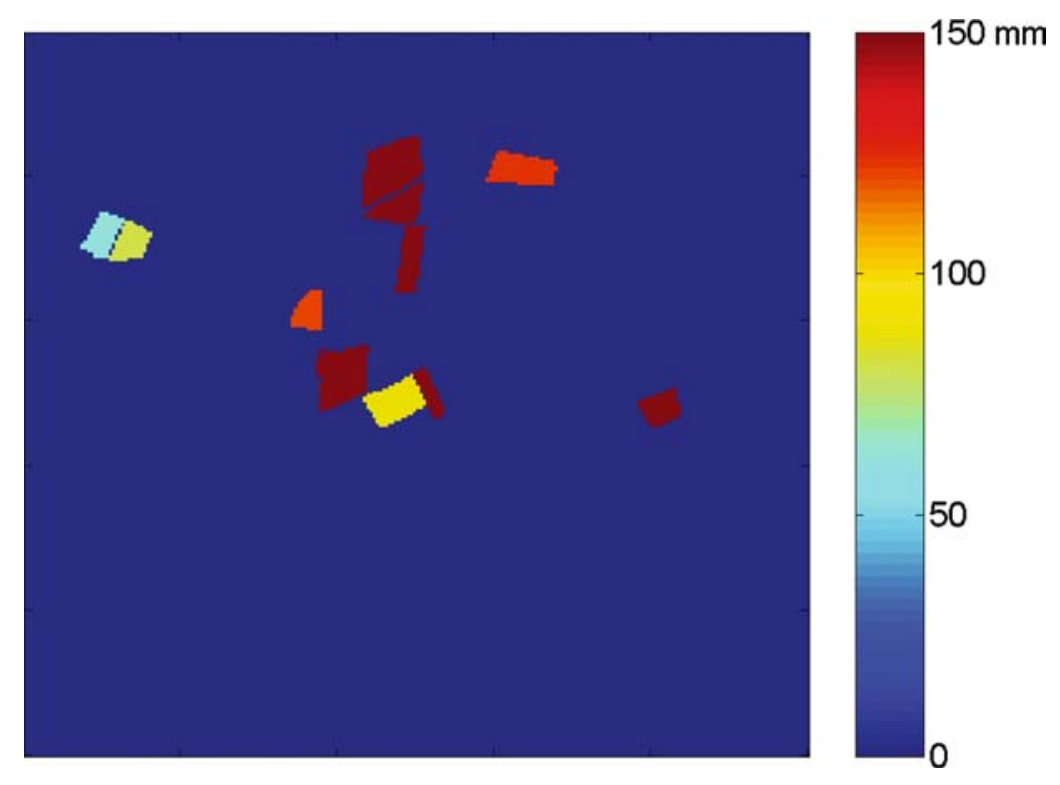

Figure 11. $5 \mathrm{~km} \times 5 \mathrm{~km}$ maps of irrigation supplies (in $\mathrm{mm}$ ) in the wheat fields of the Alpilles test zone as derived by sequential assimilation of differential surface temperatures.

field by decreasing wilting points in order to increase the simulated water soil reserve (Figure 12). Decreases in wilting point as large as $0.09 \mathrm{~m}^{3} \mathrm{~m}^{-3}$ were required in some fields. Large changes occurred in many fields in the Southern and the Western area of the Alpilles site. This may be in agreement with the distribution of soil types, soils in these two areas containing less clay than in the central part. One single determination of wilting point and field capacity was done in the Western area. It gave values in agreement with a decrease in wilting point: $w_{\mathrm{wp}}=0.146 \mathrm{~m}^{3} \mathrm{~m}^{-3}$ and $w_{\mathrm{fc}}=0.337 \mathrm{~m}^{3} \mathrm{~m}^{-3}$ (Olioso et al., 2002a). The spatial adjustment of wilting point made it possible to derive evapotranspiration maps of wheat fields over the test area. Figure 13 displays the map of integrated evapotranspiration from February to the end of June 1997.

In a fifth step, we compared derived evapotranspiration to field measurements available in three contrasted fields. Soil moisture and soil water potential measurements and rain amount were used for deriving the integrated evapotranspiration using a soil water balance approach (similar to the one used in Ortega-Farias et al., 2004) giving $305 \mathrm{~mm}$ in a field sown in November $1996,359 \mathrm{~mm}$ in a field also sown in November, but which was irrigated in early April, and $245 \mathrm{~mm}$ in a field sown in February 1997. Averaged evapotranspiration obtained from assimilation of remote sensing data on the same fields and over the same period were $287 \mathrm{~mm}$ with a standard deviation (S.D.) 


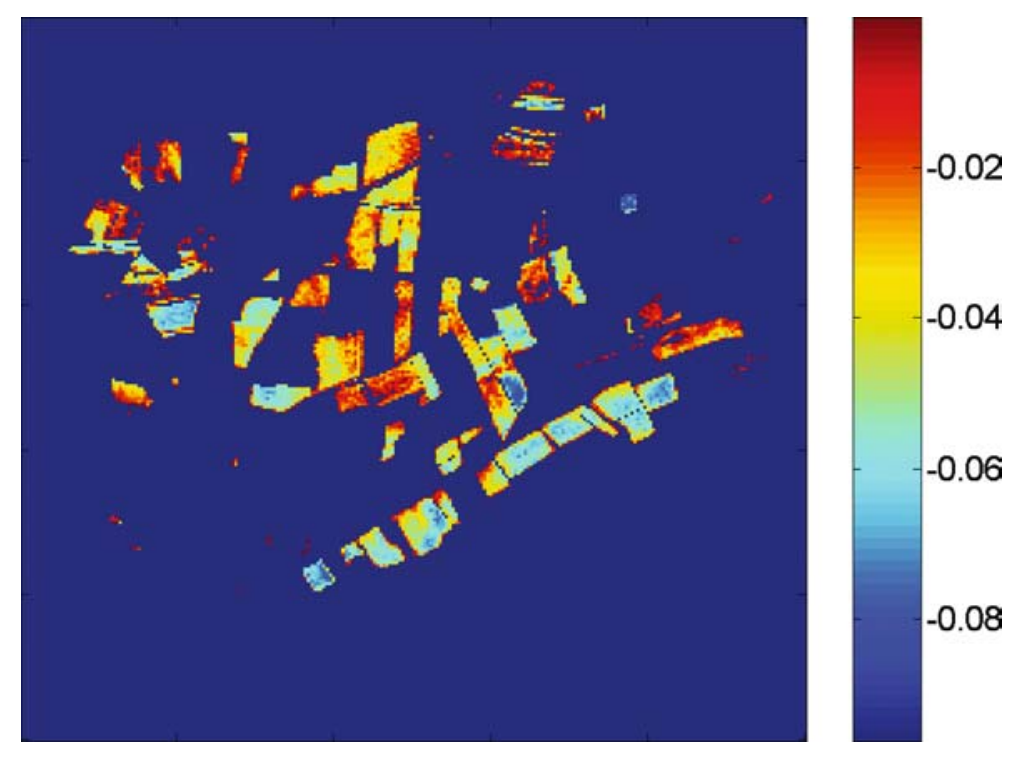

Figure 12. Wilting point variations (in $\mathrm{m}^{3} \mathrm{~m}^{-3}$ ) over the $5 \mathrm{~km} \times 5 \mathrm{~km}$ Alpilles area as computed from remote sensing data assimilation (variational assimilation of surface temperature).

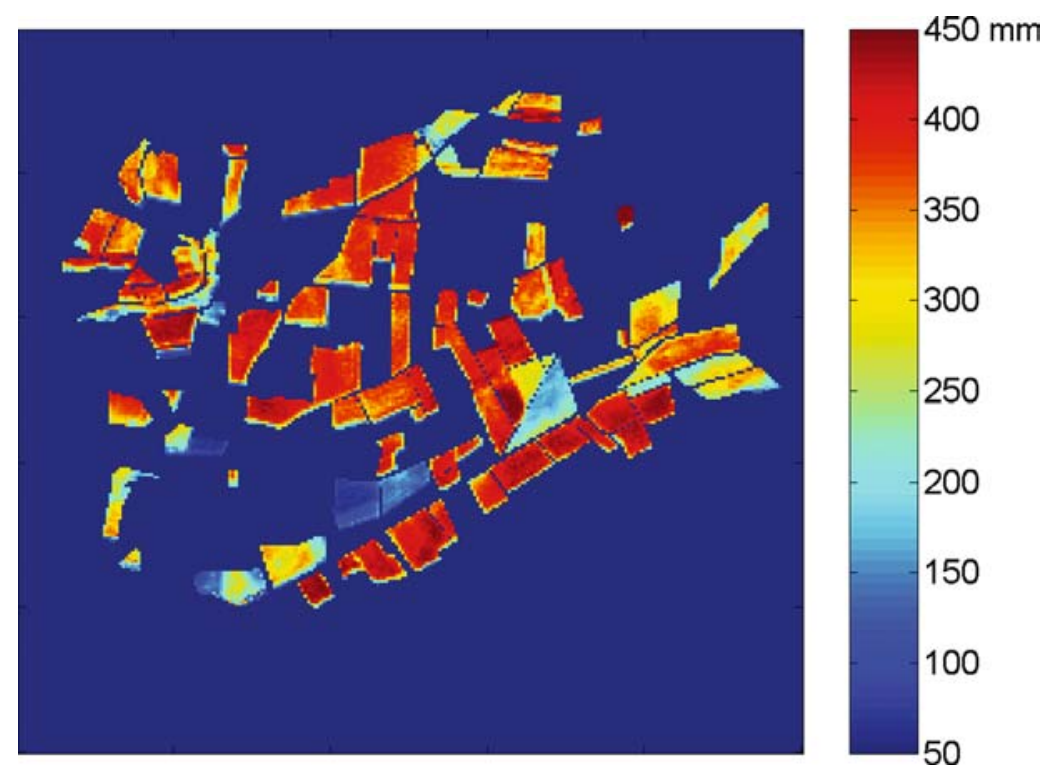

Figure 13. $5 \mathrm{~km} \times 5 \mathrm{~km}$ maps of cumulated evapotranspiration (in $\mathrm{mm}$ ) of wheat crops between January and June as derived from assimilation of remote sensing data. 
of $40 \mathrm{~mm}, 345 \mathrm{~mm}($ S.D. $=61 \mathrm{~mm})$ and $195 \mathrm{~mm}($ S.D. $=30 \mathrm{~mm})$, respectively. When compared to ground data, the remote sensing estimates led to a root mean square difference of $31 \mathrm{~mm}$ (which was mainly due to a mean underestimation around 10\%). However, standard deviations of remote sensing estimations were high, which made difficult the comparison to ground data. The high-field variability was mainly due to the high level of water stress that affected wheat crops this particular year. No rain occurred for almost 3 months and wheat growth was strongly depressed by water shortage: for example, maximum LAI observed in each of the three previous fields were $1.5,2.5$ and 1 , respectively.

Other comparisons will be made in the future, in particular to evapotranspiration maps obtained by Jacob et al. (2002a), Wassenaar et al. (2002) and Olioso et al. (2002c) over the whole area with various energy balance models, such as SEBAL or the 'simplified relationship'. Finally, it is important to notice that if these results were obtained from airborne remote sensing data, we expect that they would have been almost similar if real satellite data were used. Main differences concerned the spatial resolution of the TIR sensor, which was $20 \mathrm{~m}$ in our case, and the possibility of deriving accurate surface temperature from TIR data. In this study, TIR airborne data were calibrated with a lot of care, including the comparison to ground measurements, a procedure that won't be available in operational situation. Two ways for overcoming this difficulty may be investigated in the future: (i) using multispectral TIR sensors which allow accurate atmospheric and emissivity corrections (e.g. Jacob et al., 2004); (ii) exploiting the spatial variability of images in order to derive quantities which are less sensitive to atmospheric correction as it is done for example in SEBAL (e.g. the works by Moran et al., 1996; Droogers \& Bastiaanssen, 2002; Schuurmans et al., 2003 suggest to assimilate flux maps instead of surface temperature maps) or by directly taking advantages of the spatial variability of temperature in the image as it is partially done in this study (Figure 10) or in previous works, e.g. by Carlson et al. (1990; Gillies et al., 1997).

\section{Discussion and conclusion}

After introducing some crop and SVAT models, we have presented simple examples illustrating various types of procedures to assimilate remote sensing data into these models. We showed that these procedures made it possible to monitor evapotranspiration, soil moisture, plant growth and in some cases irrigation events.

The results presented in this article illustrated some of the advantages of using SVAT or crop models in combination with remote sensing data to derive evapotranspiration and crop water processes. 
1. This approach provides a continuous monitoring of evapotranspiration, while this may be difficult when using classical evapotranspiration mapping methods (such as SEBAL). Allen et al. (2005), have shown that an extrapolation of evapotranspiration from the day of the satellite image to days between images was possible by deriving crop coefficients for each image and combining them to the reference evapotranspiration that is computed every day. It will be interesting to compare such method to the use of crop or SVAT models, in particular in conditions in which crop coefficients may change rapidly while the period between successive remote sensing data acquisition is large. The issue of interpolating remote sensing estimation is very important since present remote sensing data with a spatial resolution fine enough to monitor agricultural fields (Landsat data for instance) cannot always be obtained with an adequate time frequency.

2. Crop or SVAT models may also be used to monitor evapotranspiration without utilising TIR remote sensing data, which is not possible when using classical mapping methods. As shown in Figures 8 and 9, the interaction between crop growth processes and water processes makes it possible to use reflectances or radar data even in condition of water stress. It may be also relatively easy, even if this was not yet fully proved, to combine data from remote sensing systems with different acquisition frequencies (e.g. SPOT, Landsat and ERS). As a matter of fact, combination of reflectances and radar data has been proven to be effective in studies by Bouman (1992), Clevers and van Leeuwen (1996) and Prévot et al. (2003; note that this study was done by assimilating data into STICS over some of the wheat fields of the Alpilles-ReSeDA experiment). The combination of reflectances and TIR data was illustrated in this article over the Alpilles test site. We will focus future studies on the analysis of possible synergy between various remote sensing data for driving SVAT and crop models.

3. Another advantage we find when using SVAT or crop models, comes from the possible simulation of many processes other than evapotranspiration (soil water balance, crop growth, crop production) as well as their interactions with crop management practices. For instance, ISBA-Ags provides simulations of biomass and LAI. STICS, as a crop model, provides simulation of crop phenology, biomass production, LAI and yield components. It may be used for analysing the relation between yield, irrigation and nitrogen supply management.

Of course, the use of crop and SVAT models has drawbacks. For instance: (i) they require the setting of a large number of parameters, not all of them obtainable by assimilating remote sensing data (ISBA and ISBA-Ags have around 10 additional parameters; STICS has 10 times more); at the moment no study has fully assessed that problem and little has been done to understand 
the interactions between model parameters, expected simulation accuracy, availability and accuracy of input data (remote sensing data, ancillary parameters, meteorological inputs); (ii) crop and SVAT models require continuous inputs of meteorological data (at least hourly for SVAT models and daily for crop models) and may be highly sensitive to the spatial variation of such data (which may be not the case for model exploiting the spatial variability of images such as SEBAL); (iii) crop and SVAT models require soil information (at least field capacity and wilting point) and plant physiological information (stomatal conductance, response to water stress and so on) which are not easy to obtain over large areas (even if assimilation of remote sensing data may be used in some cases); (iv) SVAT and crop models require a large computing power when applied over large areas (and even larger when using assimilation procedure).

The results presented in this paper also raised some questions. (i) Most of the results were obtained by using remote sensing data having a highacquisition frequency. The data obtained over soybean in Avignon were available almost every 2 or 3 days. However, as illustrated by the correction procedure example (Figures 6 and 7), the use of only very few data was enough for monitoring crop processes with ISBA-Ags (four acquisitions in almost 3 months in this case). The application presented over the Alpilles test area was also based on the acquisition of reflectance and TIR data almost every 2-3 weeks. On some fields within the same area, Moulin et al. (2002) and Clevers et al. (2002) showed that four images acquired over the wheat crop cycle with the SPOT-HRV instrument made it possible the calibration and the correction of a crop model and a SVAT model. (ii) Variational assimilation over the soybean dataset showed that it was not possible to retrieve simultaneously initial soil moisture and crop growth parameters because of compensations occurring between these parameters. This problem may be the major drawbacks for implementing variational assimilation procedures. It may be solved, at least in some situations, if a careful sensitivity analysis of the assimilation procedure is done in order to define precisely the parameters that should be retrieved or if some parameters are known from previous studies as for example in Wigneron et al. (2002). Olioso et al. (1999a,b) showed, with another model, that parameter compensations might be used on purpose for reducing the number of parameters to retrieve without affecting the accuracy of estimated evapotranspiration. Another direction for solving this problem may be based on stochastic procedures that may be used for retrieving groups of parameters generating evapotranspiration estimation having similar accuracy (Demarty et al., 2004 and 2005).

Nowadays, the use of assimilation procedures to drive crop and SVAT models with remote sensing data is still at its beginning. Many assimilation techniques have been developed for assimilating meteorological data (and 
some remote sensing data) in atmospheric modelling for weather forecast or for assimilating soil moisture or water flow in hydrological modelling. At the moment, none of them has been applied with significant results to the analysis of surface processes. Making use of adequate procedures is one of the first challenges for developing a quantitative use of remote sensing information in agricultural and environmental issues in the near future.

\section{Acknowledgement}

This work was partially founded by ECOS-CONICYT French-Chile cooperation program no C99U04, by the French ACI "Observation de la Terre" and by EC through the WATERMED program (contract ICA3-CT-1999-00015). The Alpilles-ReSeDA project was funded by the EEC-DG XII (contract ENVHCT96-0326-PL952071), the French Programme National de Télédétection Spatiale (PNTS) and Programme National de Recherches en Hydrologie (PNRH).

\section{References}

Allen, R.G., Morse, A. \& Tasumi, M. 2005. Application of SEBAL for western US water rights regulation and planning (this issue).

Baret, F. \& Guyot, G. 1991. Potentials and limits of vegetation indices for LAI and APAR assessment. Remote Sensing of Environment 35: 161-173.

Baret, F. (ed) 2002. Special issue: Multi-sensor and multi-temporal remote sensing observations to characterise canopy functioning. The ReSeDA project. Agronomie 22(6): 165.

Bastiaanssen, W.G.M., Menenti, M., Feddes, R.A. \& Holtslag, A.A. 1998. A remote sensing surface energy balance algorithm for land (SEBAL). I: Formulation. Journal of Hydrology 212-213: 198-212.

Bertuzzi, P., Chanzy, A., Vidal-Madjar, D. \& Autret, M. 1992. The use of a microwave backscatter model for retrieving soil moisture over bare soil. International Journal of Remote Sensing 13: 2653-2668.

Bertuzzi, P., Bruckler, L., Bay, D. \& Chanzy, A. 1994. Sampling strategies for soil water content to estimate evapotranspiration. Irrigation Science 14: 105-115.

Bouman, B.A.M. 1992. Linking physical remote sensing models with crop growth simulation models, applied for sugar beet. International Journal of Remote Sensing 13: 25652581.

Braud, I., Dantas Antonino, A.C., Vauclin, M., Thony, J.-L. \& Ruelle, P. 1995. A Simple Soil Plant Atmosphere Transfer model (SiSPAT): Development and field verification. Journal of Hydrology 166: 213-250.

Braud, I., Varado, N. \& Olioso, A. 2005. Comparison of root water uptake modules using either the surface energy balance or potential transpiration. Journal of Hydrology 301: 267-286.

Brisson, N., Olioso, A. \& Clastre, P. 1993. Daily transpiration of field soybeans as related to hydraulic conductance, root distribution, soil potential and midday leaf potential. Plant and Soil 154: 227-237.

Brisson, N., Gary, C., Justes, E., et al. 2003. An overview of the crop model STICS. European Journal of Agronomy 18: 309-332. 
Calvet, J.-C., Noilhan, J., Roujean, J.-L., Bessemoulin, P., Cabelguenne, M., Olioso, A. \& Wigneron, J.-P. 1998. An interactive vegetation SVAT model tested against data from six contrasting sites. Agricultural and Forest Meteorology 92: 73-95.

Camillo, P. 1991. Using one- and two-layer models for evaporation estimation with remotely sensed data. In: Land Surface Evaporation. Measurement and Parameterization (pp 183197). Springer-Verlag, New York, USA.

Carlson, T., Perry, E. \& Schmugge, T. 1990. Remote estimation of soil moisture availability and fractional vegetation cover for agricultural fields. Agricultural and Forest Meteorology 52: 45-69.

Cayrol, P., Kergoat, L., Moulin, S., Dedieu, G. \& Chehbouni, A. 2000. Calibrating a coupled SVAT/vegetation growth model with remotely sensed reflectance and surface temperature. A case study for the HAPEX-Sahel grassland sites. Journal of Applied Meteorology 39: 2452-2472.

Cellier, P. \& Olioso, A. 1993. A simple system for automated long-term Bowen ratio measurement. Agricultural and Forest Meteorology 66: 81-92.

Chauki, H., Prévot, L., Troufleau, D., Brisson, N., Olioso, A., Baret, F. \& Guérif, M. 2000. Assimilation of ERS and RadarSat SAR observations within STICS crop growth model (pp 485-490). Proceedings of the CEOS SAR Workshop. Toulouse, October 1999, ESA SP-450.

Clevers, J.G.P.W. \& van Leeuwen, H.J.C. 1996. Combined use of optical and microwave remote sensing data for crop growth monitoring. Remote Sensing of Environment 56: 42-51.

Clevers, J.G.P.W., Vonder, O.W., Jongschaap, R.E.E., Desprats, J.-F., King, C., Prévot, L. \& Bruguier, N. 2002. Using SPOT data for calibrating a wheat growth model under Mediterranean conditions. Agronomie 22: 687-694.

Courtier, P. \& Talagrand, O. 1990. Variational assimilation of meteorological observations with the direct and adjoint shallow-water equations. Tellus 42A: 531-549.

Daamen, C. \& Simmonds, L. 1994. SWEAT: A Numerical Model of Water and Energy Fluxes in Soil Profiles and Sparse Canopies. University of Reading, Reading, England, p 119.

Deardorff, J.W. 1978. Efficient prediction of ground surface temperature and moisture with inclusion of a layer of vegetation. Journal of Geophysical Research 20: 1889-1903.

Delécolle, R., Maas, S.J., Guérif, M. \& Baret, F. 1992. Remote sensing and crop production models: Present trends. ISPRS Journal of Photogrammetry and Remote Sensing 47: 145161.

Demarty, J., Ottlé, C., François, C., Braud, I. \& Frangi, J.P. 2002. Effect of aerodynamic resistance modeling on SiSPAT-RS simulated surface fluxes. Agronomie 22: 641-650.

Demarty, J., Ottlé, C., Braud, I., Olioso, A., Frangi, J.P., Bastidas, L.A. \& Gupta, H.V. 2004. Using a multiobjective approach to retrieve information on surface properties used in a SVAT model. Journal of Hydrology 287: 214-236.

Demarty, J., Ottlé, C., Braud, I., Olioso, A., Frangi, J.P., Gupta, H. \& Bastidas, L.A. 2005. Constraining a physically based Soil-Vegetation-Atmosphere Transfer model with surface water content and thermal infrared brightness temperature measurements using a multiobjective approach. Water Resources Research 41, W01011, doi: 10.1029/2004WR003695.

Droogers, P. \& Bastiaanssen, W. 2002. Irrigation performance using hydrological and remote sensing modeling. Journal of Irrigation and Drainage Engineering 128: 11-18.

Droogers, P., Bastiaanssen, W.G.M., Beyazgül, M., Kayam, Y., Kite, G.W. \& Murray-Rust, H. 2000. Distributed agro-hydrological modeling of an irrigation system in western Turkey. Agricultural Water Management 43: 183-202.

Duchemin, B., Maisongrande, P., Frappart, F., Chehbouni, G., Dedieu, G. \& Mougenot, B. 2002. Monitoring of wheat crop evapotranspiration and irrigation in arid conditions using phenology derived from optical satellite data (pp 177-183). First International Symposium 
on Recent Advances in Quantitative Remote Sensing, 16-20 September 2002 Valencia, Spain.

Federer, C.A. 1979. A soil-plant-atmosphere model for transpiration and availability of soil water. Water Resources Research 15: 555-562.

François, C., Cayrol, P., Kergoat, L. \& Moulin, S. 2001. Assimilation techniques of remote sensing measurements into vegetation models: Overview, limits and promises (pp 649658). Proceedings of the 8th International Symposium on Physical Measurements and Signatures in Remote Sensing, 8-12 January 2001, Aussois, France.

François, C., Quesney, A. \& Ottlé, C. 2003. Sequential Assimilation of ERS-1 SAR data into a coupled land surface-hydrological model using an extended Kalman filter. Journal of Hydrometeorology 4: 473-487.

Guerra, L.C., Hoogenboom, G., Boken, V.K., Thomas, D.L., Hook, J.E. \& Harrison, K.A. 2004. Predicting water demand for irrigation based on a crop simulation model and local weather data. 84th AMS Annual Meeting, 11-15 January 2004, Seattle, WA, USA.

Gillies, R.R., Carlson, T.N., Cui, J., Kustas, W.P. \& Humes, K.S. 1997. Verification of the 'triangle' method for obtaining surface soil water content and energy fluxes from remote measurements of the Normalized Difference Vegetation Index NDVI and surface radiant temperature. International Journal of Remote Sensing 18: 3145-3166.

Houser, P.R., Shuttleworth, W.J., Famiglietti, J.S., Gupta, H.V., Syed, K. \& Goodrich, D.C. 1998. Integration of soil moisture remote sensing and hydrologic modeling using data assimilation. Water Resources Research 34: 3405-3420.

Ines, A.V.M., Gupta, A.D. \& Loof, R. 2002. Application of GIS and crop growth models in estimating water productivity. Agricultural and Water Management 54: 205-225.

Inoue, Y. \& Olioso, A. 2004. Estimating the Dynamics of $\mathrm{CO}_{2}$ Flux in Agro-Ecosystems based on Synergy of Remote Sensing and Process Modeling - A Methodological Study. In Global Environmental Change in the Ocean and on Land, Eds., Masae Shiyomi, Hodaka Kawahata, Hiroshi Koizumi, Atsushi Tsuda and Yoshio Awaya, pp. 375-390. TERRAPUB, Tokyo.

Inoue, Y., Moran, M.S. \& Horie, T. 1998. Analysis of spectral measurements in rice paddies for predicting rice growth and yield based on a simple crop simulation model. Plant Production Science 1: 269-279.

Jacob, F., Olioso, A., Gu, X.F., Su, Z. \& Seguin, B. 2002a. Mapping surface fluxes using airborne visible, near infrared, thermal infrared remote sensing data and a spatialized surface energy balance model. Agronomie 22: 669-680.

Jacob, F., Olioso, A., Weiss, M., Baret, F. \& Hautecoeur, O. 2002b. Mapping short-wave albedo of agricultural surfaces using airborne PolDER data. Remote Sensing of Environment 80: 36-46.

Jacob, F., Petitcolin, F., Schmugge, T., Vermote, E., French, A. \& Ogawa, K. 2004. Comparison of land surface emissivity and radiometric temperature derived from MODIS and ASTER sensors. Remote Sensing of Environment 90: 137-152.

Jacobs, A.F.G., Ronda, R.J. \& Holtslag, A.A.M. 2003. Water vapour and carbon dioxide fluxes over bog vegetation. Agricultural and Forest Meteorology 116: 103-112.

Lauvernet, C., Le Dimet, F.X., Baret, F., Deboissezon, H., Favard, J.C., Vintila, R., Lazar, C. $\&$ Badea, A. 2002. Assimilation of high temporal frequency SPOT data to describe canopy functioning-The case of wheat crops in the ADAM experiment in Romania. In: J.A. Sobrino (ed) First International Symposium on Recent Advances in Quantitative Remote Sensing, 16-20 September 2002 (pp 921-926). Publicacions de la Universitat de València, España, Valencia, Spain.

Lorenc, A.C. 1997. Development of an operational variational assimilation scheme. Journal of the Meteorological Society of Japan 75: 339-346. 
Mahfouf, J.-F. \& Noilhan, J. 1996. Inclusion of gravitational drainage in a land surface scheme based on the force-restored method. Journal of Applied Meteorology 35: 987-992.

Milly, P.C.D. 1982. Moisture and heat transport in hysteretic inhomogeneous porous media: A matric head-based formulation and a numerical model. Water Resources Research 18: 489-498.

Moran, M.S., Maas, S.J., Clarke, T.R., Pinter, P.J. Jr., Qi, J., Mitchell, T.A., Kimball, B.A. \& Neale, C.M.U. 1996. Modeling/Remote Sensing Approach for Irrigation scheduling. In: C. Camp, E. Sadler \& R Yoder (eds) Evapotranspiration and Irrigation Scheduling (pp 231-238) (San Antonio, Texas), ASAE-IA-ICID, ASAE.

Moulin, S., Bondeau, A. \& Delécolle, R. 1998. Combining agricultural crop models and satellite observations: From field to regional scales. International Journal of Remote Sensing 19: 1021-1036.

Moulin, S., Kergoat, L., Cayrol, P., Dedieu, G. \& Prévot, L. 2002. Calibration of a coupled canopy functioning and SVAT model in the ReSeDA experiment. Towards the assimilation of SPOT/HRV observations into the model. Agronomie 22: 681-686.

Nijbroek, R., Hoogenboom, G. \& Jones, J.W. 2003. Optimizing irrigation management for a spatially variable soybean field. Agricultural Systems 76: 359-377.

Noilhan, J. \& Mahfouf, J.-F. 1996. The ISBA land surface parameterisation scheme. Global Planetary Changes 13: 145-159.

Nouvellon, Y., Moran, M.S., Lo Seen, D., Bryant, R., Rambal, S., Ni, W., Bégué, A., Chehbouni A., Emmerich W.E., Heilman P. \& Qi, J. 2001. Coupling a grassland ecosystem model with Landsat imagery for a 10-year simulation of carbon and water budgets. Remote Sensing of Environment 78: 131-149.

Olioso, A. 1995a. Simulating the relationship between thermal emissivity and the Normalized Difference Vegetation Index. International Journal of Remote Sensing 16: 3211-3216.

Olioso, A. 1995b. Estimating the difference between brightness and surface temperatures for a vegetal canopy. Agricultural and Forest Meteorology 72: 237-242.

Olioso, A., Carlson, T.N. \& Brisson, N. 1996a. Simulation of diurnal transpiration and photosynthesis of a water stressed soybean crop. Agricultural and Forest Meteorology 81: 41-59.

Olioso, A., Taconet, O. \& Ben Mehrez, M. 1996b. Estimation of heat and mass fluxes from IR brightness temperature. IEEE Transactions on Geoscience and Remote Sensing 34: 1184-1190.

Olioso, A., Gu, X.-F. \& Baret, F. 1997. Correction of irradiance geometry effect in field measurements of reflectance made with ground reflectometers. In: G. Guyot \& T. Phulpin (eds) Proceedings of the 7th International Symposium on Physical Measurements and Signatures in Remote Sensing (Vol. 1), (pp 123-130). April 1997, Courchevel, France, Balkema (Rotterdam, The Netherlands).

Olioso, A., Chauki, H., Courault, D. \& Wigneron, J.-P. 1999a. Estimation of evapotranspiration and photosynthesis by assimilation of remote sensing data into SVAT models. Remote Sensing of Environment 68: 341-356.

Olioso, A., Chauki, H., Wigneron, J.-P., Bertuzzi, P., Chanzy, A., Bessemoulin, P. \& Calvet, J.C. 1999b. Estimation of energy fluxes from thermal infrared, spectral reflectances, microwave data and SVAT modeling. Physics and Chemistry of the Earth Part B 24: 829-836.

Olioso, A., Inoue, Y., Wigneron, J.-P., Ortega-Farias, O., Lecharpentier, P., Pardé, M., Calvet, J.C. \& Inizan, O. 2001. Using a coupled crop-SVAT model to assess crop canopy processes from remote sensing data. In IGARSS 2001, July 2001, Sydney, Australia. IEEE Publications. CDRom paper 171. pdf, or soft-cover book vol. 7, pp. 3006-3008.

Olioso, A., Braud, I., Chanzy, A., Demarty, J., Ducros, Y., Gaudu, J.-C., Gonzalez-Sosa, E., Lewan, E., Marloie, O., Ottlé, C., Prévot, L., Thony, J.-L., Autret, H., Bethenod, O., 
Bonnefond, J.-M., Bruguier, N., Buis, J.-P., Calvet, J.-C., Caselles, V., Chauki, H., Coll, C., François, C., Goujet, R., Jongschaap, R., Kerr, Y., King, C., Lagouarde, J.-P., Laurent, J.-P., Lecharpentier, P., Mc Aneney, J., Moulin, S., Rubio, E., Weiss, M. \& Wigneron, J.-P. 2002a. Monitoring energy and mass transfers during the Alpilles-ReSeDA experiment. Agronomie 22: 597-610.

Olioso, A., Jacob, F., Hadjar, D., Lecharpentier, P. \& Hasager, C.B. 2002b. Spatial distribution of evapotranspiration and aerodynamic roughness from optical remote sensing. In: Herman Debie \& Koen de Ridder (eds) Proceedings of the International Workshop on Landscape Heterogeneity and Aerodynamic Roughness:Modelling and Remote Sensing Perspectives (pp 19-26) 12 October 2001, Antwerp, Belgique. VITO.

Olioso, A., Hasager, C., Jacob, F., Wassenaar, T., Chehbouni, A., Marloie, O., Lecharpentier, P. \& Courault, D. 2002c. Mapping surface sensible heat flux from thermal infrared and reflectances data using various models over the Alpilles test site. In: J.A. Sobrino (Ed) First International Symposium on Recent Advances in Quantitative Remote Sensing, (pp 450457). 16-20 September 2002, Valencia, Spain. Publicacions de la Universitat de València, España.

Olioso, A., Braud, I., Chanzy, A., Courault, D., Demarty, L., Kergoat, L., Lewan, E., Ottlé, C., Prévot, L., Zhao, W.G., Calvet, J.-C., Cayrol, P., Jongschaap, R., Moulin, S., Noilhan, J. \& Wigneron, J.-P. 2002d. SVAT modeling over the Alpilles-Reseda experiment: Comparing SVAT models over wheat fields. Agronomie 22: 651-668.

Olioso, A., Ortega-Farias, S., Valdés, H. \& Antonioletti, R. 2005. Estimación de la evapotranspiración de tomate usando un modelo de interacción suelo-vegetación-atmósfera Agricultura Técnica 65: 284-294.

Ortega-Farias, S., Olioso, A., Antonioletti, R. \& Brisson, N. 2004. Evaluation of the PenmanMonteith model for estimating soybean evapotranspiration. Irrigation Science 23: 1-9.

Ottlé, C. \& Vidal-Madjar, D. 1994. Assimilation of soil moisture inferred from infrared remote sensing in a hydrological model over the HAPEX-MOBILHY region. Journal of Hydrology 158: 241-264.

Panda, P.K., Behera, S.K. \& Kashyap, P.S. 2003. Effective management of irrigation water for wheat under stressed conditions. Agricultural Water Management 63: 37-56.

Prévot, L., Chauki, H., Troufleau, D., Weiss, M., Baret, F. \& Brisson, N. 2003. Assimilating optical and radar data into the STICS crop model for wheat. Agronomie 23: 297-303.

Reichle, R., McLaughlin, D.B. \& Entekhabi, D. 2001. Variational data assimilation of microwave radiobrightness observations for land surface hydrology applications. IEEE Transactions on Geosciences and Remote Sensing 39: 1708-1718.

Reichle, R.H., Walker, J.P., Koster, R.D. \& Houser, P.R. 2003. Extended versus Ensemble Kalman Filtering for Land Data Assimilation. Journal of Hydrometeorology 4: 728740 .

Rinaldi, M. 2001. Application of EPIC model for irrigation scheduling of sunflower in Southern Italy. Agricultural Water Management 49: 185-196.

Saunders, R.W. 1997. Use of remote sensing data in numerical weather prediction models. In: G. Guyot \& T. Phulpin (eds) Proceedings of the 7th International Symposium on Physical Measurements and Signatures in Remote Sensing (pp 833-839) (Vol. 2). April 1997, Courchevel, France. Balkema, Rotterdam, The Netherlands.

Schuurmans, J.M., Troch, P.A., Veldhuizen, A.A., Bastiaanssen, W.G.M. \& Bierkens, M.F.P. 2003. Assimilation of remotely sensed latent heat flux in a distributed hydrological model. Advances in Water Resources 26: 151-159.

Sellers, P.J., Randall, D.R., Collatz, G.J., et al. 1996a. A revised land-surface parameterization (SiB2) for atmospheric GCMs. Part 1: Model formulation. Journal of Climate 9: 676705 . 
Sellers, P.J., Los, S.O., Tucker, C.J., et al. 1996b. A revised land-surface parameterization (SiB2) for atmospheric GCMs. Part 2: The generation of global fields of terrestrial biophysical parameters from satellite data. Journal of Climate 9: 706-737.

Sinclair, T.R. \& Seligman, N.G. 1996. Crop modeling: From infancy to maturity. Agronomy Journal 88: 698-704.

Soer, G.J.R. 1980. Estimation of regional evapotranspiration and soil moisture conditions using remotely sensed crop surface temperature. Remote Sensing of Environment 9: 27-45.

Taconet, O. \& Vidal-Madjar, D. 1988. Application of a flux algorithm to a field-satellite campaign over vegetated area. Remote Sensing of Environment 26: 227-239.

Taconet, O., Olioso, A., Ben Mehrez, M. \& Brisson, N. 1995. Seasonal estimation of evaporation and stomatal conductance over a soybean field using surface IR temperatures. Agricultural and Forest Meteorology 73: 321-337.

Verhoef, W. 1984. Light scattering by leaf layers with application to canopy reflectance modeling: The SAIL model. Remote Sensing of Environment 16: 125-141.

Verhoef, W. \& Bach, H. 2003. Remote sensing data assimilation using coupled radiative transfer models. Physics and Chemistry of the Earth 28: 3-13.

Viovy, N., François, C., Bondeau, A., Krinner, G., Polcher, J., Kergoat, L., Dedieu, G., De Noblet, N., Ciais, P. \& Friedlingstein, P. 2001. Assimilation of remote sensing measurements into the ORCHIDEE/STOMATE DGVM Biosphere model. In Proceedings of the 8th International Symposium on Physical Measurements and Signatures in Remote Sensing (pp 713-716). 8-12 January 2001, Aussois, France.

Wassenaar, T., Olioso, A., Hasager, C., Jacob, F. \& Chehbouni, A. 2002. Estimation of evapotranspiration on heterogeneous pixels. In: J.A. Sobrino (Ed.). First International Symposium on Recent Advances in Quantitative Remote Sensing (pp 458-465). 16-20 September 2002, Valencia, Spain. Publicacions de la Universitat de València, España. .

Weiss, M., Troufleau, D., Baret, F., Chauki, H., Prévot, L., Olioso, A., Bruguier, N. \& Brisson, N. 2001. Coupling canopy functioning and radiative transfer models for remote sensing data assimilation. Agricultural and Forest Meteorology 108: 113-128.

Weiss, M., Baret, F., Leroy, M., Hautecoeur, O., Bacour, C., Prévot, L. \& Bruguier, N. 2002. Validation of neural net techniques to estimate canopy biophysical variables from remote sensing data. Agronomie 22: 547-553.

Wigneron, J.-P., Chanzy, A., Calvet, J.C. \& Bruguier, N. 1995. A simple algorithm to retrieve soil moisture and vegetation biomass using passive microwave measurements over crop fields. Remote Sensing of Environment 51: 331-441.

Wigneron, J.-P., Olioso, A., Calvet, J.-C. \& Bertuzzi, P. 1999a. Estimating root-zone soil moisture from surface soil moisture data and soil-vegetation-atmosphere transfer modeling. Water Resources Research 35: 3735-3745.

Wigneron, J.-P., Ferrazzoli, P., Olioso, A., Bertuzzi, P. \& Chanzy, A. 1999b. A simple approach to monitor crop biomass from C-band radar data. Remote Sensing of Environment 69: $179-188$.

Wigneron, J.-P., Chanzy, A., Calvet, J.-C., Olioso, A. \& Kerr, Y. 2002. Modeling approaches to assimilating L-band passive microwave observations over land surfaces. Journal of Geophysical Research 107(D14): 10.1029/2001JD000958.

WMO, 1995. International Programme Committee (D.L.T. Anderson, A.F. Bennett, P. Courtier, R. Daley, M. Ghil (Chair); K. Ide (Secretary) M. Kubota, K. Puri, P. Malanotte-Rizzoli, N. Sato, O. Talagrand (eds) Proceedings of the Second WMO International Symposium on Assimilation of Observations in Meteorology and Oceanography, Vols. I \& II (p 717), Tokyo, March 1995, WMO/TD-No. 651, PWPR Report Series No. 5, World Meteorological Organization, Geneva, Switzerland. 